DOE/ID/13451

Nonaqueous Electrolyte Development for Electrochemical Capacitors

T. R. Jow

K. Xu

S. P. Ding

September 1999

Work Performed Under Contract No. DE-AI07-96ID13451

For

U.S. Department of Energy

Assistant Secretary for

Energy Research

Washington, DC

By

U.S. Army Research Laboratory

Adelphi, MD 
DOE/ID/13451

\title{
NONAQUEOUS ELECTROLYTE DEVELOPMENT FOR ELECTROCHEMICAL CAPACITORS
}

\author{
T. R. Jow \\ K. Xu \\ S. P. Ding
}

September 1999

Work Performed Under Contract No. DE-AI07-96ID13451

Prepared for the U.S. Department of Energy

Assistant Secretary for

Energy Research

Washington, DC

Prepared by

U.S. Army Research Laboratory

Adelphi, MD 


\section{Contents}

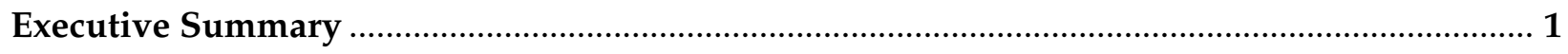

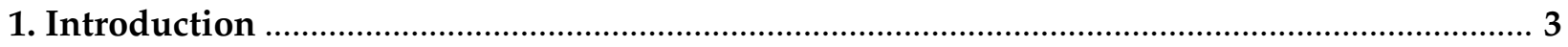

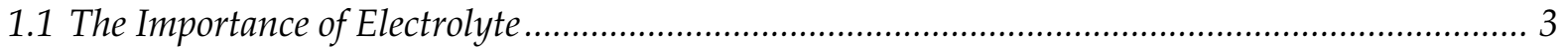

1.2 Desired Properties and Controlling Parameters ……………………………………………... 5

1.3 State-of-the-Art Nonaqueous Electrolytes .......................................................................... 5

1.4 Recent Development …………………………………………………………………. 5

Electrolytes Based on Quaternary Ammonium Salts .................................................... 5

Electrolytes Based on Cyclic Aromatic Imidazolium Salts ............................................ 6

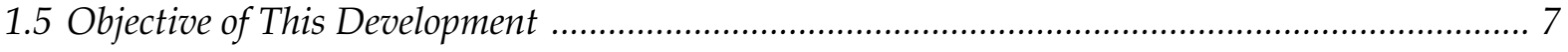

2. Synthesis of New Asymmetric Quaternary Ammonium Salts .............................................. 8

2.1 Methods of Syntheses ................................................................................................... 8

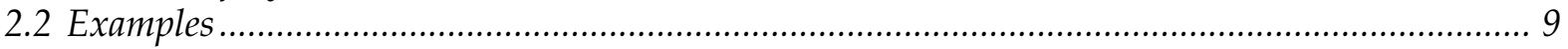

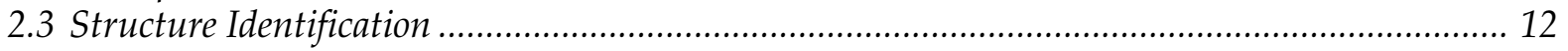

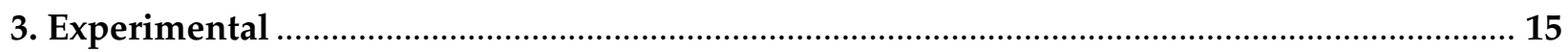

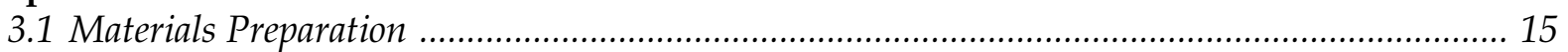

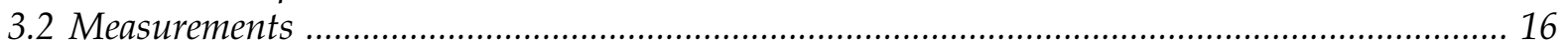

Melting Point (or Decomposition Temperatures) and Solubility ................................... 16

Electrical Conductivity ....................................................................................... 16

Electrochemical Stability Window …………………………………………….... 16

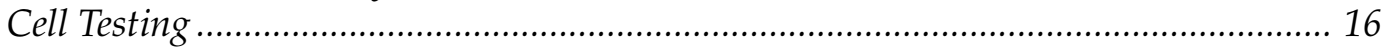

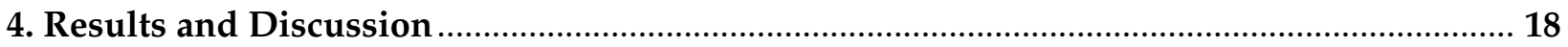

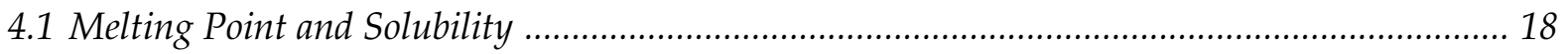

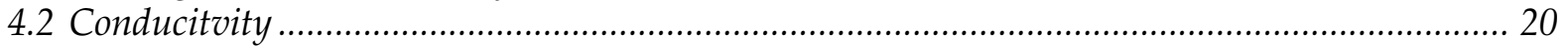

Conductivity of Electrolytes Containing Et4NBF4 and Et4NPF6 ............................. 20

Conductivity of Electrolytes Containing Asymmetric Quaternary Ammonium Salts ... 20

4.3 Electrochemical Stability ........................................................................................... 24

Electrochemical Stability versus Glassy Carbon ........................................................ 24

Electrochemical Stability versus Porous Activated Carbon Electrodes ........................... 26

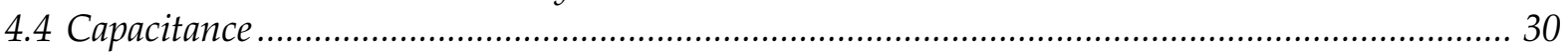

4.5 A Comparison of ARL Electrolytes With the State-of-the-Art Electrolytes ................................... 30

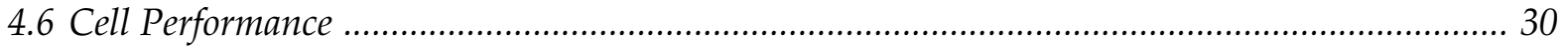

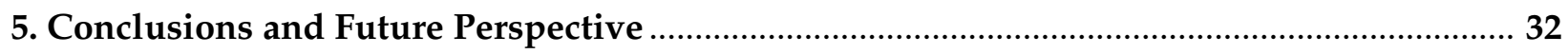

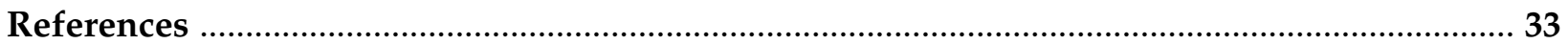

Figures

Figure 1.1: Comparisons of energy density vs. average power density for Panasonic capacitors containing $0.65 \mathrm{M} \mathrm{Et}_{4} \mathrm{NBF}_{4}$ in $\mathrm{PC}$ and $1.60 \mathrm{M} \mathrm{Et}_{4} \mathrm{NBF}_{4}$ in $\mathrm{AN}$ at $20{ }^{\circ} \mathrm{C}$.................................... 4

Figure 2.1: NMR spectra of tripropylmethylammonium cation ...................................................... 13

Figure 2.2: NMR spectra of triethylmethylammonium cation .......................................................... 13

Figure 2.3: NMR spectra of diisopropylethylmethylammonium cation ........................................ 14

Figure 4.1: The correlation of melting point and solubility of asymmetry quaternary ammonium salts (in 50:50 EC-DMC) with variations in cation. Commercially available $\mathrm{Et}_{4} \mathrm{NPF}_{6}$ is used as a control

Figure 4.2: Room temperature electrolytic conductivities of EC-DMC (50:50 by wt.) solutions of asymmetric quaternary ammonium salts at different salt concentrations ........................... 20 
Figure 4.3: Conductivity vs. temperature from -40 to $70^{\circ} \mathrm{C}$ for electrolytes containing $0.65 \mathrm{M}$ $\mathrm{Et}_{4} \mathrm{NBF}_{4}$ in various solvent systems. $\left(\diamond: 10 \mathrm{~N} \mathrm{H}_{2} \mathrm{SO}_{4}\right.$ solution, $\bullet: 0.87 \mathrm{M} \mathrm{Et}_{4} \mathrm{NBF}_{4}$ in $\mathrm{AN}, \mathbf{\Delta}$ : $0.84 \mathrm{M} \mathrm{Et}_{4} \mathrm{NBF}_{4}$ in $\mathrm{AN} / \mathrm{EC}\left(50 / 50\right.$ by wt.), $: 0.65 \mathrm{M} \mathrm{Et}_{4} \mathrm{NBF}_{4}$ in AN/PC, $\square: 0.65 \mathrm{M}$ $\mathrm{Et}_{4} \mathrm{NBF}_{4}$ in $\mathrm{EC} / \mathrm{PC} / \mathrm{AN}(42.5 / 42.5 / 15), \nabla: 0.65 \mathrm{M} \mathrm{Et}_{4} \mathrm{NBF}_{4}$ in BL, O : $0.65 \mathrm{M} \mathrm{Et}_{4} \mathrm{NBF}_{4}$ in $\mathrm{BL} / \mathrm{EC}(50 / 50), \Delta: 0.65 \mathrm{M} \mathrm{Et}_{4} \mathrm{NBF}_{4}$ in $\mathrm{EC} / \mathrm{PC}, \mathbf{\square}: 0.65 \mathrm{M} \mathrm{Et}_{4} \mathrm{NBF}_{4}$ in PC)....

Figure 4.4: Change of electrolytic conductivity with salt concentration for electrolytes $\mathrm{Et}_{4} \mathrm{NPF}_{6}(\mathrm{a})$ and $\mathrm{Et}_{3} \mathrm{MeNPF}_{6}(\mathrm{~b})$ in EC-DMC (50:50) at various temperatures ........................ 22

Figure 4.5: Electrolytic conductivity vs. salt concentration at temperatures from -15 to $60{ }^{\circ} \mathrm{C}$

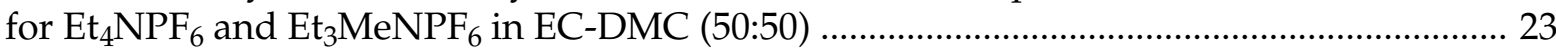

Figure 4.6: Change of conductivity with the size of the cations in tetraalkylammonium hexafluorophosphates for EC-DMC (50:50 by wt.) electrolytes containing such salts ........... 23

Figure 4.7: Limiting molar conductivities of two electrolytes, $\mathrm{Et}_{3} \mathrm{MeNPF}_{6}$ and $\mathrm{Et}_{4} \mathrm{NPF}_{6}$, respectively, in EC-DMC (50:50) at different temperatures. Those of $\mathrm{KCl}$ in water are plotted for reference and comparison

Figure 4.8: Linear sweep voltammograms for electrolyte solutions of $\mathrm{Et}_{4} \mathrm{NPF}_{6}$ and $\mathrm{Et}_{3} \mathrm{MeNPF}_{6}$ in EC-DMC (50:50) on glassy carbon. That for $\mathrm{Et}_{4} \mathrm{NPF}_{6}$ in $\mathrm{AN}$ is plotted for comparison

Figure 4.9: Comparison of cathodic stability of various onium cations synthesized ................... 25

Figure 4.10: The total electrochemical stability window of a conventional ammonium salt

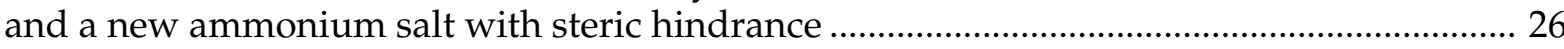

Figure 4.11: Comparison of anodic stability of various anions ................................................... 27

Figure 4.12: The CV curve of an electrolyte against a porous activated carbon electrode. Instead of a zero background current, a large background current was observed. Within the stability window, there is only non-Faradaic charge $Q N F$, (or capacitive charging current) but no Faradaic charge $Q F$. The $Q F$-to- $Q N F$ ratio, $R$, should be zero when the voltages are within the stability window

Figure 4.13: New method for the quantification of electrolyte stability range on activated carbon

Figure 4.14: The electrochemical stability range of electrolyte 1.0 $\mathrm{M} \mathrm{Et}_{4} \mathrm{NPF}_{6}$ in EC-DMC (50:50) according to the new quantification

Figure 4.15: The electrochemical stability window of several electrolytes containing $1.0 \mathrm{M}$ $\mathrm{Et}_{3} \mathrm{MeNPF}_{6}$ in solvent systems such as PC, EC-DMC, EC, and EMSF-DMC determined by the new quantification method....

Figure 4.16: Charge/discharge voltage profile of a Panasonic GoldCap ${ }$, capacitor in original electrolyte (lower curve) and in $1.0 \mathrm{M} \mathrm{Et}_{3} \mathrm{MeNPF}_{6}$ in EC-DMC (upper curve) ......

\section{Tables}

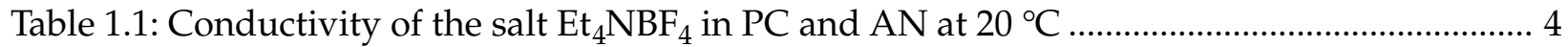

Table 1.2: Energy limitations of the state-of-the-art carbon-based capacitors (calculated

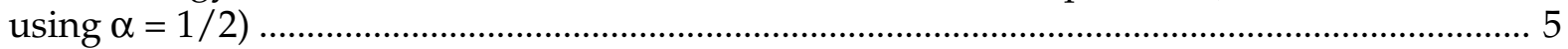

Table 1.3: Desired electrolyte properties and controlling parameters .......................................... 6

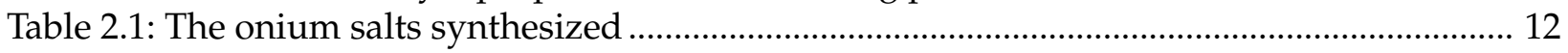

Table 3.1: Physical properties of selected solvents .......................................................................... 15

Table 3.2: Estimated ionic radii (r), molecular weight (MW), and single ion-limiting conductivity $(\lambda \mathrm{o})$

Table 4.1: Comparison of $\mathrm{Et}_{4} \mathrm{NPF}_{6}$ and $\mathrm{Et}_{3} \mathrm{MeNPF}_{6}$ salts .......................................................... 18

Table 4.2: Conductivities of electrolytes containing $\mathrm{Et}_{4} \mathrm{NBF}_{4}$ in various solvent systems at a concentration of $0.65 \mathrm{M}$ and at the saturated concentration.... 21

Table 4.3: A comparison of ARL electrolytes with the state-of-the-art electrolytes..... 31 


\section{Acknowledgments}

Wishvender Behl, Mark Salomon, and Jim Zheng made valuable contributions in the early stages of the project. However, before we moved from Fort Monmouth, NJ, to Adelphi, MD, Mr. Salomon retired in June 1997, Dr. Zheng left ARL in July 1997 to join the faculty of Florida A\&M University/Florida State University, and Dr. Behl began to devote his time to a different project.

The authors are especially grateful to Harold Haskins and Mati Mikkor of the Partnership for a New Generation of Vehicles (PNGV) and Ray Sutula of the Department of Energy (DOE). Without their support, we would not have achieved as much as we did. 


\section{Executive Summary}

The U.S. Army Research Laboratory (ARL) has been actively involved in development of nonaqueous electrolytes for rechargeable lithium (Li) batteries since the early 1970s. ARL has also been engaged in the development of capacitors for pulsed-power applications since 1989. We concentrated on film capacitors originally, as we were faced with requirements for extreme high-power densities (electromagnetic launchers). We shifted to electrolytic capacitors and finally to electrochemical pseudo-capacitors based on amorphous ruthenium oxides (1-5) as our requirements shifted to the need for higher energy densities and more modest power densities for transportation and burst communications. With our knowledge of and experience in electrolytes and capacitors, we recently started to investigate a lower cost carbon-based double-layer capacitor using nonaqueous electrolytes. As there are similarities in the electrolytes for batteries and electrochemical capacitors, we believe that we can make a significant contribution in this area.

Electrochemical capacitors are attractive to use because of their long cycle life and inherent high-power (or fast charge/discharge) capabilities. To realize the inherent high-power nature of the capacitor, the resistance of the capacitor needs to be low. The resistance of the capacitors comes from two parts: the electronic part and the ionic part. The main focus of this project, however, is on the ionic part of capacitor resistance. The ionic resistance is largely determined by the electrolyte, especially the electrolyte's conductivity. In double-layer capacitors, the electrolyte also functions as an active material that provides the necessary ionic charges for charging the electrolyte and electrode interface. Therefore, in addition to high conductivity, a high ion concentration becomes one of the key parameters that needs to be improved for highperformance nonaqueous electrolytes.

The objectives of this project were to demonstrate and develop new nonaqueous electrolytes that enable the development of high power in excess of $2 \mathrm{~kW} / \mathrm{kg}$ and high energy in excess of $8 \mathrm{Wh} / \mathrm{kg}$ capacitors. To achieve these objectives, the ideal electrolytes should possess the following characteristics:

High conductivity: $\sigma>20$ to $40 \mathrm{mS} / \mathrm{cm}$ at room temperature

High salt concentration: $\mathrm{C}>1.5 \mathrm{M}$

Large electrochemical stability window: $\Delta \mathrm{V}>3 \mathrm{~V}$

Wide operating temperature range: -40 to $70^{\circ} \mathrm{C}$

Thermally stable: -40 to $70^{\circ} \mathrm{C}$

Environmentally benign.

To achieve the objectives of this project, two approaches were used. The first approach was to search for the proper solvent mixtures within the commercially available quaternary ammonium salts such as tetraethyl ammonium tetrafluoroborate $\left(\mathrm{Et}_{4} \mathrm{NBF}_{4}\right)$ or tetraethyl ammonium hexafluorophosphate $\left(\mathrm{Et}_{4} \mathrm{NPF}_{6}\right)$. The second approach was to use the commonly available solvent systems but develop new salts. We believe that we will be able to achieve our goal by using salts with proper cation and anion combinations.

In searching for the proper solvent mixtures using the commercially available salts $\mathrm{Et}_{4} \mathrm{NBF}_{4}$ and $\mathrm{Et}_{4} \mathrm{NPF}_{6}$, we found that the solubility of these salts in the solvent mixtures that we investigated does not reach our objective of having a greater than 1.5-M concentration except in acetonitrile (AN) and ethylene carbonate (EC). The solubility of $\mathrm{Et}_{4} \mathrm{NBF}_{4}$ in $\mathrm{AN}$ is $1.68 \mathrm{M}$ at room temperature and its conductivity at room temperature is $57 \mathrm{mS} / \mathrm{cm}$ at a $1.65-\mathrm{M}$ 
concentration. We observed substantial improvement in power performance for Panasonic's GoldCap ${ }^{\circledR}$ capacitors over that for capacitors using the original electrolyte of $0.65 \mathrm{M} \mathrm{Et}_{4} \mathrm{NBF}_{4}$ in propylene carbonate (PC). However, AN's lower oxidative stability and high vapor pressure make it unsuitable for long life and high-temperature applications. Although the solubility of $\mathrm{Et}_{4} \mathrm{NBF}_{4}$ in $\mathrm{EC}$ is $1.625 \mathrm{M}$ at room temperature, its solubility decreases substantially at low temperatures.

Our effort was then directed to the second approach, developing salts that can be dissolved more than $1.5 \mathrm{M}$ in the commonly used solvent systems. We also wanted the electrolytes containing these salts to be stable with respect to electrodes at the same time. Our literature survey suggested that quaternary ammonium salts are the most stable salts compared with other classes of salts. We decided to systematically synthesize a series of quaternary ammonium salts with different asymmetric cation and anion combinations. Thus far, we have synthesized 13 different salts. We observed a substantial increase in solubility when the cation was changed from a symmetric structure such as tetraethyl ammonium to an asymetric structure such as triethylmethyl ammonium. For example, the solubility of $\mathrm{Et}_{4} \mathrm{NPF}_{6}$ in EC-DMC is $1.46 \mathrm{M}$, while the solubility of $\mathrm{Et}_{3} \mathrm{MeNPF}_{6}$ in EC-DMC is $3.13 \mathrm{M}$. The conductivity of the electrolyte containing asymmetric quaternary ammonium salts is similar to that of the electrolyte containing symmetric ones at the same salt concentration. Since the asymmetric salts can be dissolved to a greater degree, the conductivity of these electrolytes can reach a higher value than that of the symmetric ones, reaching over $20 \mathrm{mS} / \mathrm{cm}$ at room temperature.

The electrochemical stability window of the electrolyte containing new salts was slightly improved due to an improvement in the reductive stability of the cation. This improvement comes from the steric protection of the alkyl substituents. To obtain a realistic value of the stability window for a practical carbon material, the traditional method is to use an arbitrary current value as a limit to determine the voltage limit, but this does not work for the high surface area of carbon materials. A new method that uses charge, or an integration of current, instead of using current directly to detect the instability limit gave us values that more realistically reflect the true stability window. Using the new method and new salts, we learned that the stability window of the electrolyte also varies with the solvent. Our study was not exhaustive; however, it is important in that we found that the sulfone-based solvent achieved a stability window as high as $3.5 \mathrm{~V}$.

A demonstration of the new electrolyte, especially $\mathrm{Et}_{3} \mathrm{MeNPF}_{6}$ in EC-DMC, using a prototype cell from Maxwell Technologies was started at the end of the project. However, the required amount of purified electrolyte and the time needed to complete the tests were beyond the scope of the present project.

In summary, we have made substantial advances in quaternary ammonium salts and identified solvent systems that can withstand high voltage operations. However, improvement in the salt alone is not sufficient. Improvements in the low-temperature stability of a capacitor rely not only on the salts but also on the solvents. Likewise, the high-temperature stability of the capacitor will depend not only on the salts but also on the solvents and carbon electrode materials. Much remains to be accomplished, especially in exploring solvents and carbon materials. The next phase of our work will require the participation of (i) a capacitor manufacturer for carbon electrode fabrication and capacitor assembly and (ii) a chemical company for electrolyte preparation and purification. 


\section{Introduction}

\subsection{The Importance of Electrolyte}

The electrolyte in electrochemical capacitors is generally recognized as one of the key components that determine the ionic of the capacitor and, thus, the power capability and the deliverable energy content of the capacitor. The other component is the electronic resistance, which includes the electrodes and the cell assembly. This is beyond the scope of this report and will not be discussed here. Therefore, the conductivity of the electrolyte is our primary concern.

At ARL, our initial effort started with a search for electrolytes with conductivity higher than that of the electrolyte used in the commercially available state-of-the-art double-layer capacitors, such as Panasonic's GoldCap ${ }^{\circledR}$ capacitor. This capacitor uses $0.65 \mathrm{M}$ of tetraethylammonia tetrafluoroborate in propylene carbonate $\left(\mathrm{Et}_{4} \mathrm{NBF}_{4} / \mathrm{PC}\right)(\mathbf{6})$ as an electrolyte. The conductivity of this electrolyte is only $8.8 \mathrm{mS} / \mathrm{cm}$ at room temperature. We replaced the electrolyte in the GoldCap ${ }^{\circledR}$ capacitor with the electrolyte of $\mathrm{Et}_{4} \mathrm{NBF}_{4}$ in acentonitrile (AN). This electrolyte has a conductivity of $43.0 \mathrm{mS} / \mathrm{cm}$ and $57.2 \mathrm{mS} / \mathrm{cm}$ at a concentration of $0.65 \mathrm{M}$ and $1.60 \mathrm{M}$, respectively, at $20^{\circ} \mathrm{C}$. A comparison of these two electrolytes is shown in table 1.1. As shown in figure 1.1, both the energy density and the power density of the GoldCap ${ }^{\circledR}$ capacitor improved significantly with a higher conductivity electrolyte.

In charging a double-layer capacitor, the charges are accumulated and separated at the interface between the electronic conducting electrodes and the ionic conducting electrolyte. The ionic charges that move to the interface from the electrolyte match the electronic charges from the electrodes. Therefore, the electrolyte functions not only as a media for ionic conduction but also as a source for ionic charge. Since the solubility of salt in nonaqueous solvent is not as high as that in water, the sufficient supply of the ionic charges becomes an issue that we cannot ignore. ARL is the first to recognize the importance of this aspect of the electrolyte for a capacitor $(7,8)$. When the ionic charge is considered, the energy density of the capacitor is no longer expressed as being based solely on the electrode materials, as shown by

$$
E=\frac{1}{8} c_{p} V^{2}
$$

where $c_{p}$ is the specific capacitance of the electrode material and $V$ is the operating voltage of the capacitor, which is limited by the decomposition potential of the electrolyte. The correct expression for the energy density should be (7)

$$
E=\frac{1}{8} c_{p} V^{2} \frac{1}{1+\frac{c_{p} V}{4 a c_{0} F}},
$$

where $c_{o}$ is the salt concentration of the electrolyte; $F$ is the Faraday constant and equals 96,500 coulomb / M; and $a$, which is a unitless constant less than 1, represents the fraction of ions removed from the bulk of the electrolyte. Equation [2] clearly indicates that only when the ion concentration $c_{o}$ is much greater than the charge capacity of the electrode $c_{p} V$ can the energy density of the double-layer capacitor be smaller than the usually conceived value as expressed in equation [1]. 
Table 1.1: Conductivity of the salt $\mathrm{Et}_{4} \mathrm{NBF}_{4}$ in $\mathrm{PC}$ and $\mathrm{AN}$ at $20^{\circ} \mathrm{C}$.

\begin{tabular}{llc}
\hline Solvent & Salt concentration $(\mathrm{M})$ & $\sigma(\mathrm{mS} / \mathrm{cm})$ \\
\hline PC & 0.65 & 8.8 \\
PC & 0.86 (saturated) & 12.4 \\
AN & 0.65 & 43.0 \\
AN & 1.68 (saturated) & 57.2 \\
\hline
\end{tabular}

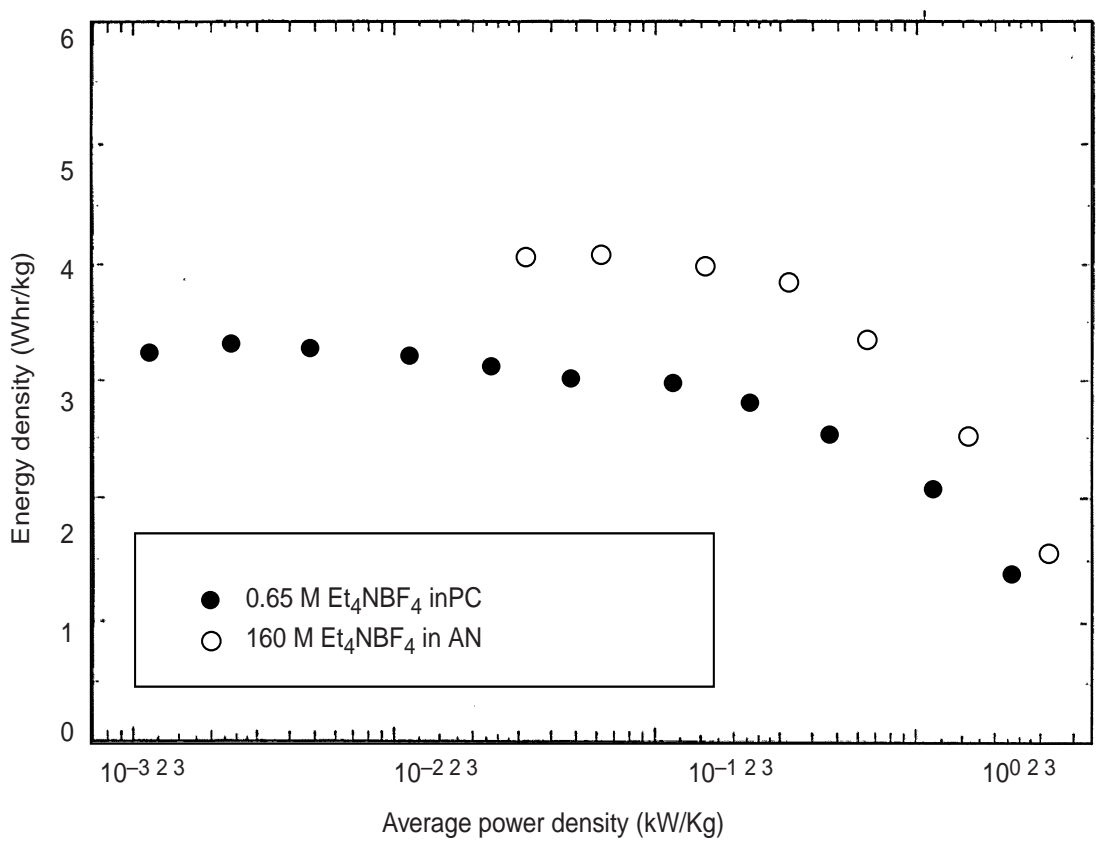

Figure 1.1: Comparisons of energy density vs. average power density for Panasonic capacitors containing $0.65 \mathrm{M} \mathrm{Et}_{4} \mathrm{NBF}_{4}$ in $\mathrm{PC}$ and $1.60 \mathrm{M} \mathrm{Et}_{4} \mathrm{NBF}_{4}$ in $\mathrm{AN}$ at $20^{\circ} \mathrm{C}$.

Table 1.2 lists the maximum energy densities calculated using equation [2] for the state-ofthe-art carbon-based double-layer capacitors in both aqueous and nonaqueous electrolytes. To achieve an energy density greater than $15 \mathrm{Wh} / \mathrm{kg}$, as shown in the table, a nonaqueous electrolyte with a salt concentration greater than $1.5 \mathrm{M}$ needs to be developed.

Based on the above consideration, it is important for electrolytes to have a high ion (or salt) concentration not only for high conductivity but also for high energy density. The high decomposition voltages of nonaqueous electrolytes allow a capacitor to operate at over $2.3 \mathrm{~V}$ as compared with $1.0 \mathrm{~V}$ for aqueous electrolytes. For energy density concerns, it is more advantageous to use nonaqueous electrolytes because the energy increases with the square of the voltage. However, the solubility of salt in a nonaqueous solvent is not as high as that in water; thus, having a sufficient supply of ionic charges becomes an issue that we cannot ignore.

The electrolytes also affect the capacitance of the electrode material as evidenced by a capacitance of $280 \mathrm{~F} / \mathrm{g}$ observed for high surface area carbon in aqueous electrolyte and $120 \mathrm{~F} / \mathrm{g}$ observed for the same carbon in nonaqueous electrolyte. Even in the same solvents, different values of capacitance are observed when the salts are different. As reported by Morita et al. (9), 
Table 1.2: Energy limitations of the state-of-the-art carbon-based capacitors (calculated using $\alpha=1 / 2$ ).

\begin{tabular}{|c|c|c|c|c|c|}
\hline $\begin{array}{l}\text { Capacitor } \\
\text { system }\end{array}$ & Electrolyte & $\begin{array}{l}\text { Maximum } \\
\text { voltage } \\
\text { (V) }\end{array}$ & $\begin{array}{c}c_{p} \\
(\mathrm{~F} / \mathrm{g})\end{array}$ & $\begin{array}{l}\text { Energy density } \\
\quad(\mathrm{Wh} / \mathrm{kg}) \\
\text { (electrode } \\
\text { material only) }\end{array}$ & $\begin{array}{c}\text { Energy density } \\
(\mathrm{Wh} / \mathrm{kg}) \\
\text { (electrode and } \\
\text { electrolyte } \\
\text { materials only) }\end{array}$ \\
\hline Carbon/aqueous & $\begin{array}{l}5.26 \mathrm{M} \\
\mathrm{H}_{2} \mathrm{SO}_{4}\end{array}$ & 0.8 & 280 & 6.22 & 4.83 \\
\hline Carbon/aqueous & $\begin{array}{l}5.26 \mathrm{M} \\
\mathrm{KOH}\end{array}$ & 0.8 & 280 & 6.22 & 5.11 \\
\hline Carbon/nonaqueous & $\begin{array}{l}0.75 \mathrm{M} \\
\mathrm{Et}_{4} \mathrm{NBF}_{4} / \mathrm{PC}\end{array}$ & 3.0 & 120 & 37.5 & 9.69 \\
\hline Carbon/nonaqueous & $\begin{array}{l}1.5 \mathrm{M} \\
\text { electrolyte }\end{array}$ & 3.0 & 120 & 37.5 & 15 \\
\hline
\end{tabular}

the discharge capacitance of the model capacitors is about $10 \mathrm{~F} / \mathrm{g}$ in $0.5 \mathrm{M} \mathrm{Bu}_{4} \mathrm{NBF}_{4}$ in EC+ $\gamma \mathrm{BL}$ ( $50 / 50$ by mol) but is about $16 \mathrm{~F} / \mathrm{g}$ in $0.5 \mathrm{M} \mathrm{Et}_{4} \mathrm{NBF}_{4}$ in the same solvent mixtures. The difference can be attributed to the larger size of cation $\mathrm{Bu}_{4} \mathrm{~N}^{+}$than $\mathrm{Et}_{4} \mathrm{~N}^{+}$.

\subsection{Desired Properties and Controlling Parameters}

From the above observation, we summarized the properties of the desired electrolyte and the controlling parameters in table 1.3.

\subsection{State-of-the-Art Nonaqueous Electrolytes}

The electrolyte used in state-of-the-art capacitors contains tetraethylammonium tetrafluoroborate $\left(\mathrm{Et}_{4} \mathrm{NBF}_{4}\right)$ in propylene carbonate $(\mathrm{PC})$ as described in patents by Matsushita (6) or in acetonitrile (AN) as described by Maxwell Technologies (10). These electrolytes have their disadvantages.

The electrolyte of $\mathrm{Et}_{4} \mathrm{NBF}_{4}$ in $\mathrm{PC}$ exhibits a low salt concentration (saturated concentration is $0.86 \mathrm{M}$ at room temperature) and low conductivity $(8.8 \mathrm{mS} / \mathrm{cm}$ at $0.65 \mathrm{M}$ at room temperature). This electrolyte is suitable for low-power applications such as memory protection but not for high-power applications.

For high-power applications, the electrolyte of $\mathrm{Et}_{4} \mathrm{NBF}_{4}$ in $\mathrm{AN}$ is used because of its high conductivity (about $50 \mathrm{mS} / \mathrm{cm}$ at $1.4 \mathrm{M}$ at room temperature). The saturated salt concentration is about $1.68 \mathrm{M}$ at room temperature, which is more concentrated than that in PC. The AN's lower oxidative stability and high vapor pressure make it less desirable for long life and hightemperature applications.

\subsection{Recent Development}

Better nonaqueous electrolytes for capacitors and Li-ion batteries are being intensively pursued. The selection of salt and solvent (or solvent mixture) is crucial in determining the overall electrolyte properties. However, in this project, we will concentrate mostly on the effect of salt. The recent development in the area of new salts for capacitors is reviewed below. 
Table 1.3: Desired electrolyte properties and controlling parameters.

\begin{tabular}{|c|c|}
\hline Desired properties & Parameters \\
\hline$\sigma>10 \mathrm{mS} / \mathrm{cm}$ & $\begin{array}{l}\text { solvents, salts } \\
\left(\varepsilon, \eta, \mu, r_{\text {ion }} c_{o}\right), T\end{array}$ \\
\hline$\Delta \mathrm{V}>3 \mathrm{~V}$ & solvents, salts, $T$, carbon \\
\hline $\begin{array}{l}c_{o}>1.5 \mathrm{M} \\
\Delta \mathrm{T}:-40 \text { to } 70{ }^{\circ} \mathrm{C}\end{array}$ & $\begin{array}{l}\text { solvents, salts, } T \\
\text { solvents, salts, } c_{o}, T_{m}\end{array}$ \\
\hline$c_{p}>120 \mathrm{~F} / \mathrm{g}$ & solvents, salts, $c_{0}, T$, carbon \\
\hline \multicolumn{2}{|c|}{$\begin{array}{l}\text { Key } \\
\sigma: \text { conductivity of electrolyte } \\
\Delta V: \text { operating voltage window } \\
c_{0}: \text { salt concentration } \\
T: \text { temperature } \\
\Delta T: \text { operating temperature range } \\
c_{p}: \text { specific capacitance of electrode material } \\
\varepsilon \text { : permittivity of solvent } \\
\eta: \text { viscosity of solvent } \\
\mu \text { : mobility of ions } \\
r_{\text {ion }}: \text { radius of ion } \\
T_{m}: \text { melting temperature of solvent. }\end{array}$} \\
\hline
\end{tabular}

\section{Electrolytes Based on Quaternary Ammonium Salts}

Ue et al. (11-13) reported recently that the solubility of the tetraalkyl ammonium salt in PC is substantially increased when asymmetry is introduced in the cation. For example, the solubility of $\mathrm{Et}_{4} \mathrm{NBF}_{4}$ salt with a symmetric cation in $\mathrm{PC}$ is less than $1 \mathrm{M}$ at room temperature, while the solubility of $\mathrm{Et}_{3} \mathrm{MeNBF}_{4}$ with an asymmetric cation in PC is increased to $2 \mathrm{M}$ at the same temperature.

Ue et al. (11-13) also reported that the solubility can be substantially increased by using a larger anion such as bis(trifluoromethylsulfonyl)imide $\left(\mathrm{Im}^{-1}\right)$ for a symmetric or an asymmetric quaternary ammonium cation.

The improvement in conductivity as a result of the increased solubility is only slight. At room temperature $\left(25^{\circ} \mathrm{C}\right)$, the conductivity of $\mathrm{Et}_{4} \mathrm{NBF}_{4}$ in $\mathrm{PC}$ is $12 \mathrm{mS} / \mathrm{cm}$ at a concentration $\leq 1 \mathrm{M}$, while the conductivities of $2-\mathrm{M} \mathrm{Et}_{3} \mathrm{MeNBF}_{4}$ or $2-\mathrm{M} \mathrm{Et}_{4} \mathrm{NIm}$ in PC are 16 and $10 \mathrm{mS} / \mathrm{cm}$, respectively.

The stability of $\mathrm{Et}_{4} \mathrm{NBF}_{4}$ in $\mathrm{PC}$ as compared with that of $\mathrm{Et}_{3} \mathrm{MeNBF}_{4}$ in $\mathrm{PC}$ is about the same. The limiting reduction and oxidation potentials for $\mathrm{Et}_{4-\mathrm{n}} \mathrm{Me}_{\mathrm{n}} \mathrm{NBF}_{4}$, where $\mathrm{n}=0-2$, in PC are -3.0 and $3.60 \mathrm{~V}$ versus SCE (or 0.286 and $6.886 \mathrm{vs}$. $\mathrm{Li}^{+} / \mathrm{Li}$ ), respectively.

\section{Electrolytes Based on Cyclic Aromatic Imidazolium Salts}

McEwen et al. (14) recently described electrolytes containing salts based on aromatic imidazolium cations. Interestingly, many of these salts are liquids at room temperature. 
Solubility as high as over $3.5 \mathrm{M}$ is obtainable in PC with salts having aromatic ethylmethyl imidazolium cation $\left(\mathrm{EMI}^{+}\right)$.

To extend the liquid range, organic solvents are used with these salts. The conductivity of $2 \mathrm{M}$ EMI PF${ }_{6}$ in $\mathrm{PC}$ is similar to that of $2 \mathrm{M} \mathrm{Et}_{3} \mathrm{MeNBF}_{4}$ in $\mathrm{PC}$ with a value of about $16 \mathrm{mS} / \mathrm{cm}$ at room temperature $(\mathbf{1 4}, \mathbf{1 5})$. The conductivity can reach as high as $60 \mathrm{mS} / \mathrm{cm}$ when $\mathrm{AN}$ is used as the solvent.

The reported electrochemical stability windows are 4.0 to $4.4 \mathrm{~V}$ for EMIIm and 1,2-dimethyl-3-propyl imidazolium (DMPIX)Im ionic liquids, respectively (15-18). The electrochemical stability window of $\mathrm{EMIPF}_{6}$ and EMIIm in organic solvents varies with the solvent. In PC, the stability window is about $4.0 \mathrm{~V}$ for both $\mathrm{EMIPF}_{6}$ and EMIIm salts. We also noted that the limiting reduction potential is about $-1.9 \mathrm{~V}$ versus $\mathrm{Ag}$, or $+1.1 \mathrm{~V}$ versus $\mathrm{Li}^{+} / \mathrm{Li}$.

\subsection{Objective of This Development}

Therefore, our main interest is in finding electrolytes with a high salt concentration $(>1.5 \mathrm{M})$, high conductivity $\left(>10 \mathrm{mS} / \mathrm{cm}\right.$ in the temperature range from $-20^{\circ} \mathrm{C}$ to $\left.50{ }^{\circ} \mathrm{C}\right)$, and large stability window $(>3.0 \mathrm{~V})$.

Comparing the quaternary ammonium salts with the cyclic aromatic imidazolium salts, the electrochemical stability window of the former is about $2.2 \mathrm{~V}$ larger than that of the latter. The above two salts provide similar conductivity for the same salt concentration in the same organic solvents. Furthermore, it was interesting to learn that the solubility of the quaternary ammonium salts can be significantly affected by the cation structure. In searching for electrolytes with a high conductivity, high solubility, and high operating window, we decided to look further into the class of quaternary ammonium salts, specifically those with variations in their cation structures.

We studied the commercially available quaternary ammonium salts with symmetric cation such as $\mathrm{Et}_{4} \mathrm{NBF}_{4}$ and $\mathrm{Et}_{4} \mathrm{NPF}_{6}$ in different solvent systems. The quaternary ammonium salts with asymmetric cation, which are not commercially available, were synthesized in our laboratory. We have synthesized a number of quaternary ammonium salts, especially with variations in cation symmetry. Some of these salts also had different anions. The synthesis methods and examples are detailed in section 2.

The electrolytes containing quaternary ammonium salts with asymmetric cation were studied mostly in EC-DMC (50:50) mixed solvents. The solubility, conductivity, electrochemical stability, and capacitance of the electrolytes containing these salts in EC-DMC are presented and discussed in section 4 . 


\section{Synthesis of New Asymmetric Quaternary Ammonium Salts}

\subsection{Methods of Syntheses}

The practice of the present syntheses will employ, unless otherwise indicated, conventional techniques of synthetic chemistry, electrochemistry, and battery/capacitor engineering that are within the skill of the art. Such techniques are explained fully or partially in the literature. See, for example, March's Advanced Organic Chemistry (19), House's Modern Synthetic Chemistry (20), Houben-Weyl's Methoden der organischen Chemie (21), Hiers' text Organic Synthesis (22), U.S. patent No. 4,892,944 to Mori et al. (23), and Lindens' Handbook of Batteries (24).

All chemicals used in the syntheses were used as received. The asymmetric ammonium salts were synthesized according to the following three methods.

1. Ue-Mori Approach: Convenient for anion-introduction.

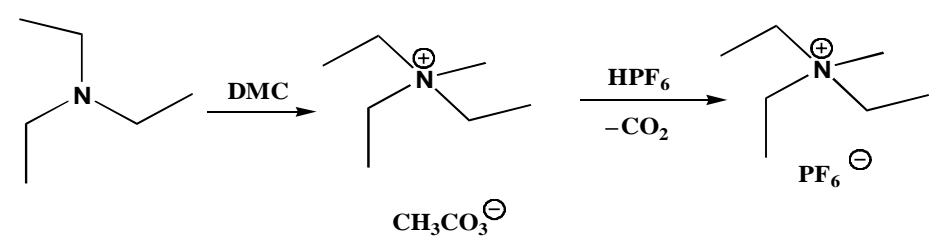

2. Modified Eschweiler-Clarke Procedure: Sterically crowded cation.

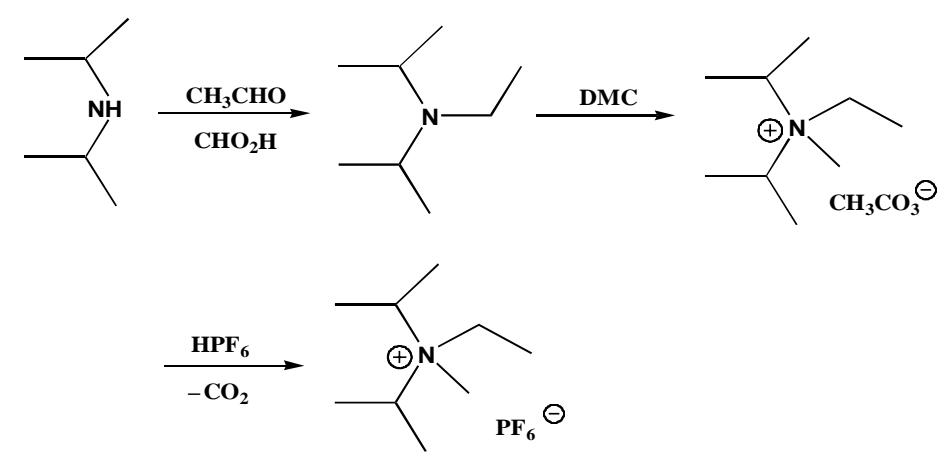

3. Controlled Exhaustive Alkylation: Very sterically hindered cation.
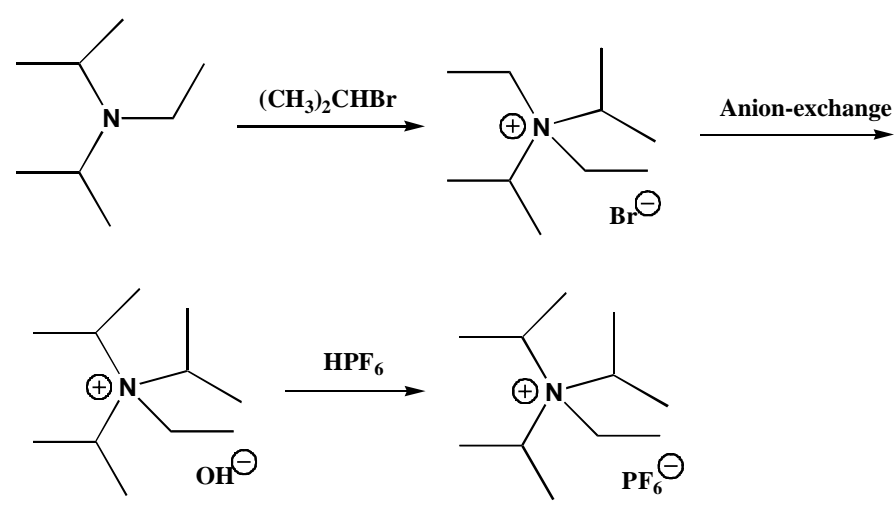


\subsection{Examples}

The steps of synthesizing the new asymmetric ammonium salts with variations in cation and anion are detailed in the following examples.

Example 1:

Synthesis of Ethylmethyldi(iso-propyl)ammonium

Hexafluorophosphate $\left(\right.$ EtMeiPr $\left.{ }_{2} \mathrm{~N}^{+} \mathrm{PF}_{6}{ }^{-}\right)$

In a 500-mL flask equipped with an addition funnel, a refluxing condenser and a stirrer were filled with $25.6 \mathrm{~g}$ of formic acid $(0.5 \mathrm{~mol}$, Aldrich, $95 \%)$ and $30.4 \mathrm{~g}$ of di(iso-propyl)amine (0.30 mol, Aldrich, 99.5\%). During cooling and while being stirred, a 13.0-g acetaldehyde solution ( $~ 0.30 \mathrm{~mol}$, Aldrich, 99\%) was slowly added. After the solution became clear, the reaction mixture was brought to $\sim 90$ to $110^{\circ} \mathrm{C}$ in an oil bath. A vigorous evolution of $\mathrm{CO}_{2}$ began after $2 \sim 3$ min., during which time the flask was removed from the bath from time to time until the evolution subsided. After $30 \mathrm{~min}$., the reaction mixture stabilized and was kept in the oil bath at $100{ }^{\circ} \mathrm{C}$ for $8 \mathrm{hr}$.

After the solution cooled, $80 \mathrm{~mL}$ of $4.0 \mathrm{~N} \mathrm{HCl}$ was added and the solution was evaporated until dry under reduced pressure. The remaining residue was dissolved in water and the organic phase was liberated by the addition of a 50-mL 9.0- $\mathrm{N} \mathrm{NaOH}$ solution. The organic phase was separated and dried with anhydrous $\mathrm{K}_{2} \mathrm{CO}_{3}$. Distillation yielded $\sim 32.0 \mathrm{~g}$ of ethyldi(isopropyl)amine.

The above amine was mixed with $22.5 \mathrm{~g}$ of dimethylcarbonate $(0.25 \mathrm{~mol}$, Aldrich, $99 \%)$ in $100 \mathrm{~mL}$ of methanol. The mixture was then added to a Parr minireactor and the temperature was brought up to $130{ }^{\circ} \mathrm{C}$ for $5 \mathrm{hr}$. under vehement stirring. After the reaction, the product was transferred to a flask and evaporated under reduced pressure. The brownish residue, ethylmethyldi(iso-propyl)ammonium methylcarbonate $\left(\mathrm{EtMeiPr}_{2} \mathrm{NMeCO}_{3}\right)$, weighs $\sim 50.0 \mathrm{~g}$.

EtMeiPr $\mathrm{NMeCO}_{3}$ was dissolved in distilled water, and $60 \%$ hexafluorophosphoric acid $\left(\mathrm{HPF}_{6}\right)$ was added to this solution with precaution. After neutralization, the solution was evaporated under reduced pressure to remove water. The resultant crystal was repeatedly recrystallized from a hot methanol solution, and the final product obtained, EtMeiPr $\mathrm{NPF}_{6}$, is fine needle crystal.

$$
\begin{gathered}
\text { Example 2: } \\
\text { Synthesis of Ethylmethyldi(iso-propyl)ammonium } \\
\text { Bis(trifluoromethane sulfonyl)imide (EtMeiPr } \left.\mathrm{N}^{+} \mathrm{Im}^{-}\right)
\end{gathered}
$$

We dissolved $40 \mathrm{~g}$ of lithium bis(trifluoromethane sulfonyl)imide $(0.14 \mathrm{~mol}, 99 \%, 3 \mathrm{M})$ in $200 \mathrm{~mL}$ of distilled water and passed it through a preprotonated cation exchange column of 4.5 equivalent capacity. The collected acid solution was once again passed through the regenerated cation exchange column to ensure quantitative conversion. The resultant aqueous solution of bis(trifluoromethane sulfonyl)imidic acid was condensed to $\sim 2.0 \mathrm{M}$ by evaporating the excess water.

The aqueous solution of bis(trifluoromethane sulfonyl)imidic acid was added to a solution of EtMeiPr $\mathrm{NMeCO}_{3}$. After the neutralization, the solution was evaporated under reduced pressure to remove water. The resultant solid was repeatedly recrystallized from a hot methanol solution, and the final product obtained, EtMeiPr${ }_{2} \mathrm{~N}^{+} \mathrm{Im}^{-}$, is fine needle crystal. 


$$
\begin{gathered}
\text { Example 3: } \\
\text { Synthesis of Ethylmethyldi(iso-propyl)ammonium } \\
\text { Triflate }\left(\text { EtMeiPr }_{2} \mathrm{~N}^{+} \mathrm{Tf}^{-}\right)
\end{gathered}
$$

A triflic acid aqueous solution was prepared in a similar procedure as described in example 2, and it was then used to neutralize the solution of EtMeiPr $\mathrm{NMeCO}_{3}$. After the neutralization, the solution was evaporated under reduced pressure to remove water. The resultant solid was repeatedly recrystallized from a hot methanol solution, and the final product obtained, EtMeiPr ${ }_{2} \mathrm{~N}^{+} \mathrm{Tf}^{-}$, is fine crystal.

Example 4:

Synthesis of Tri(iso-butyl)methyl ammonium Hexafluorophosphate $\left(\mathrm{iBu}_{3} \mathrm{MeN}^{+} \mathrm{PF}_{6}^{-}\right)$

We charged $40.0 \mathrm{~g}$ of tri(iso-butyl)amine (0.21 mol, Aldrich, $98 \%)$ and $30.0 \mathrm{~g}$ of methyliodide ( $0.21 \mathrm{~mol}$, Aldrich, $99 \%)$ in $200 \mathrm{~mL}$ of alcohol in a Parr minireactor. The reaction temperature was kept at $60{ }^{\circ} \mathrm{C}$ for $5 \mathrm{hr}$. before the reactor was opened. With the solvent evaporated under reduced pressure, the remaining solid residue was dissolved in water and passed through a strong base (in $\mathrm{OH}^{-}$form) anion exchange column with 4.0 equivalent capacity. The resultant basic solution was passed through the regenerated column again to ensure complete conversion.

After condensation, the basic solution was neutralized with $\mathrm{HPF}_{6}$ and then the solution was evaporated under reduced pressure to remove water. The resultant solid was repeatedly recrystallized from a hot methanol solution, and the final product obtained, $\mathrm{iBu}_{3} \mathrm{MeN}^{+} \mathrm{PF}_{6}^{-}$, is fine crystal.

\section{Example 5:}

Synthesis of Tri(iso-propyl)methylammonium Hexafluorophosphate $\left(\mathrm{iPr}_{3} \mathrm{MeN}^{+} \mathrm{PF}_{6}^{-}\right.$)

We mixed $40 \mathrm{~g}$ of di(isopropyl)amine (0.40 mol, Aldrich, $99.5 \%)$ in $100 \mathrm{~mL}$ of methanol with $51.2 \mathrm{~g}$ of formic acid (1.0 mol, Aldrich, 95\%) in a 500-mL flask. While it was cooling and being stirred, we slowly added $33 \mathrm{~g}$ of formaldehyde solution ( 0.40 mol, Aldrich, 37\%). After the solution became clear, the reaction mixture was brought to $\sim 90$ to $110{ }^{\circ} \mathrm{C}$ in an oil bath. A vigorous evolution of $\mathrm{CO}_{2}$ began after $2 \sim 3$ min., during which time the flask was removed from the bath from time to time until the evolution subsided. After $30 \mathrm{~min}$., the reaction mixture stabilized and was kept in the oil bath at $100{ }^{\circ} \mathrm{C}$ for $8 \mathrm{hr}$.

After the solution cooled, $100 \mathrm{~mL}$ of $4.0-\mathrm{N} \mathrm{HCl}$ was added and the solution was evaporated until dry under reduced pressure. The remaining residue was dissolved in water and the organic phase was liberated by the addition of $80 \mathrm{~mL}$ of $9.0-\mathrm{N} \mathrm{NaOH}$ solution. The organic phase was separated and dried with anhydrous $\mathrm{K}_{2} \mathrm{CO}_{3}$. Distillation yielded $\sim 34.0 \mathrm{~g}$ of methyldi(iso-propyl)amine.

We slowly added $37.0 \mathrm{~g}$ of 2-bromopropane ( $0.30 \mathrm{~mol}$, Aldrich, 99\%) to the methyldi(isopropyl)amine as obtained above. The reaction mixture was kept at room temperature overnight while being stirred. The crystal that formed was filtered and washed by methanol. The procedures for converting the crystal, which is methyltri(iso-propyl)ammnium bromide, into the corresponding hydroxide by anion exchange column, the subsequent neutralization with $\mathrm{HPF}_{6}$, and the recrystallization in methanol is described in example 4. The resultant $\mathrm{iPr}_{3} \mathrm{MeNPF}_{6}$ is fine crystal. 
Example 6:

Synthesis of Methyltripropylammonium Hexafluorophosphate $\left(\operatorname{Pr}_{3} \mathrm{MeN}^{+} \mathrm{PF}_{6}^{-}\right)$

In a Parr minireactor, we charged $28.6 \mathrm{~g}$ of tripropylamine ( $0.2 \mathrm{~mol}$, Aldrich, $99 \%)$ and 18.0 dimethylcarbonate $(0.2 \mathrm{~mol}$, Aldrich, $99 \%)$ in $200 \mathrm{~mL}$ of methanol. The reaction mixture was kept at $120^{\circ} \mathrm{C}$ overnight, and the solvent and unreacted carbonate or amine were removed through evaporation under reduced pressure.

The brownish residue, $\mathrm{Pr}_{3} \mathrm{MeN}^{+} \mathrm{MeCO}_{3}{ }^{-}$, was dissolved in distilled water, and neutralization was carried out with $\mathrm{HPF}_{6}$. The subsequent recrystallization procedure is described in example 3.

Example 7:

Synthesis of Ethyldimethylsulfonium Hexafluorophosphate $\left(\mathrm{EtMe}_{2} \mathrm{~S}^{+} \mathrm{PF}_{6}{ }^{-}\right)$

We slowly added $15 \mathrm{~g}$ of ethylmethyl sulfide ( $0.20 \mathrm{~mol}$, Aldrich, $99 \%)$ to $100 \mathrm{~mL}$ of a methyliodide solution in t-butyl methyl ether $(0.20 \mathrm{~mol}$, Aldrich, $2.0 \mathrm{M})$, and the reactants were kept at room temperature overnight. The crystalline precipitate was collected by filtration, washed by diethylether, and then dissolved in distilled water.

The procedures of converting the crystal, which is ethyldimethylsulfonium iodide, into the corresponding hydroxide by anion exchange column, the subsequent neutralization with $\mathrm{HPF}_{6}$, and recrystallization in methanol are described in example 4. The resultant EtMe $\mathrm{SPF}_{6}$ is fine crystal.

\section{Example 8:}

Synthesis of Triethylmethylammonium Hexafluorophosphate $\left(\mathrm{Et}_{3} \mathrm{MeN}^{+} \mathrm{PF}_{6}^{-}\right)$

The synthesis of $\mathrm{Et}_{3} \mathrm{MeN}^{+} \mathrm{MeCO}_{3}{ }^{-}$and its conversion into $\mathrm{Et}_{3} \mathrm{MeN}^{+} \mathrm{PF}_{6}{ }^{-}$by means of anion exchange were conducted in a similar manner as described in example 6, except that an appropriate amount of triethylamine was used in place of tripropylamine. The resultant $\mathrm{Et}_{3} \mathrm{MeN}^{+} \mathrm{PF}_{6}{ }^{-}$ is fine crystal.

\section{Example 9:}

Synthesis of Triethylmethylammonium Bis(trifluoromethane sulfonyl)imide $\left(\mathrm{Et}_{3} \mathrm{MeN}^{+} \mathrm{Im}^{-}\right)$

Using a 2.0-M aqueous solution of bis(trifluoromethane sulfonyl)imidic acid, whose preparation is described in example 2, an aqueous solution of $\mathrm{Et}_{3} \mathrm{MeN}^{+} \mathrm{MeCO}_{3}{ }^{-}$was neutralized. After the neutralization, the solution was evaporated under reduced pressure to remove water. The resultant solid was repeatedly recrystallized from a hot methanol solution, and the final product, $\mathrm{Et}_{3} \mathrm{MeN}^{+} \mathrm{Im}^{-}$, is fine needle crystal.

$$
\begin{gathered}
\text { Example 10: } \\
\text { Synthesis of Triethylmethylammonium Triflate }\left(\mathrm{Et}_{3} \mathrm{MeN}^{+} \mathrm{Tf}^{-}\right)
\end{gathered}
$$

Using a 2.0-M aqueous solution of triflic acid, whose preparation is described in example 3 , an aqueous solution of $\mathrm{Et}_{3} \mathrm{MeN}^{+} \mathrm{MeCO}_{3}{ }^{-}$was neutralized. After the neutralization, the solution was evaporated under reduced pressure to remove water. The resultant solid was repeatedly recrystallized from a hot methanol solution, and the final product, $\mathrm{Et}_{3} \mathrm{MeN}^{+} \mathrm{Tf}^{-}$, is fine needle crystal. 
Example 11:

Synthesis of Triethylmethylphosphonium Hexafluorophosphate $\left(\mathrm{Et}_{3} \mathrm{MeP}^{+} \mathrm{PF}_{6}^{-}\right)$

The synthesis of $\mathrm{Et}_{3} \mathrm{MeP}^{+} \mathrm{MeCO}_{3}{ }^{-}$and its conversion into $\mathrm{Et}_{3} \mathrm{MeP}^{+} \mathrm{PF}_{6}{ }^{-}$by means of anion exchange were conducted in a similar manner as described in example 6, except that an appropriate amount of triethylphosphine was used in place of tripropylamine. The resultant $\mathrm{Et}_{3} \mathrm{MeP}^{+} \mathrm{PF}_{6}^{-}$is fine crystal.

\section{Example 12:}

Synthesis of Tributylmethylphosphonium Hexafluorophosphate $\left(\mathrm{Bu}_{3} \mathrm{MeP}^{+} \mathrm{PF}_{6}^{-}\right)$

The synthesis of $\mathrm{Bu}_{3} \mathrm{MeP}^{+} \mathrm{MeCO}_{3}{ }^{-}$and its conversion into $\mathrm{Bu}_{3} \mathrm{MeP}^{+} \mathrm{PF}_{6}{ }^{-}$by means of anion exchange were conducted in a similar manner as described in example 6, except that an appropriate amount of tributylphosphine was used in place of tripropylamine. The resultant $\mathrm{Et}_{3} \mathrm{MeP}^{+} \mathrm{PF}_{6}{ }^{-}$is fine crystal.

The onium salts that we have synthesized are summarized with their cations and anions listed in table 2.1.

\subsection{Structure Identification}

The structure of the new salts synthesized in this work was characterized using the nuclear magnetic resonance (NMR) method. Figures 2.1 to 2.3 show the NMR spectra of some representative new salts synthesized in this work. In all cases, the chemical structure of the expected salt is confirmed by both the chemical shifts of proton nuclei signals as well as by the coupling (or splitting pattern) between the neighboring proton nuclei.

Table 2.1: The onium salts synthesized.

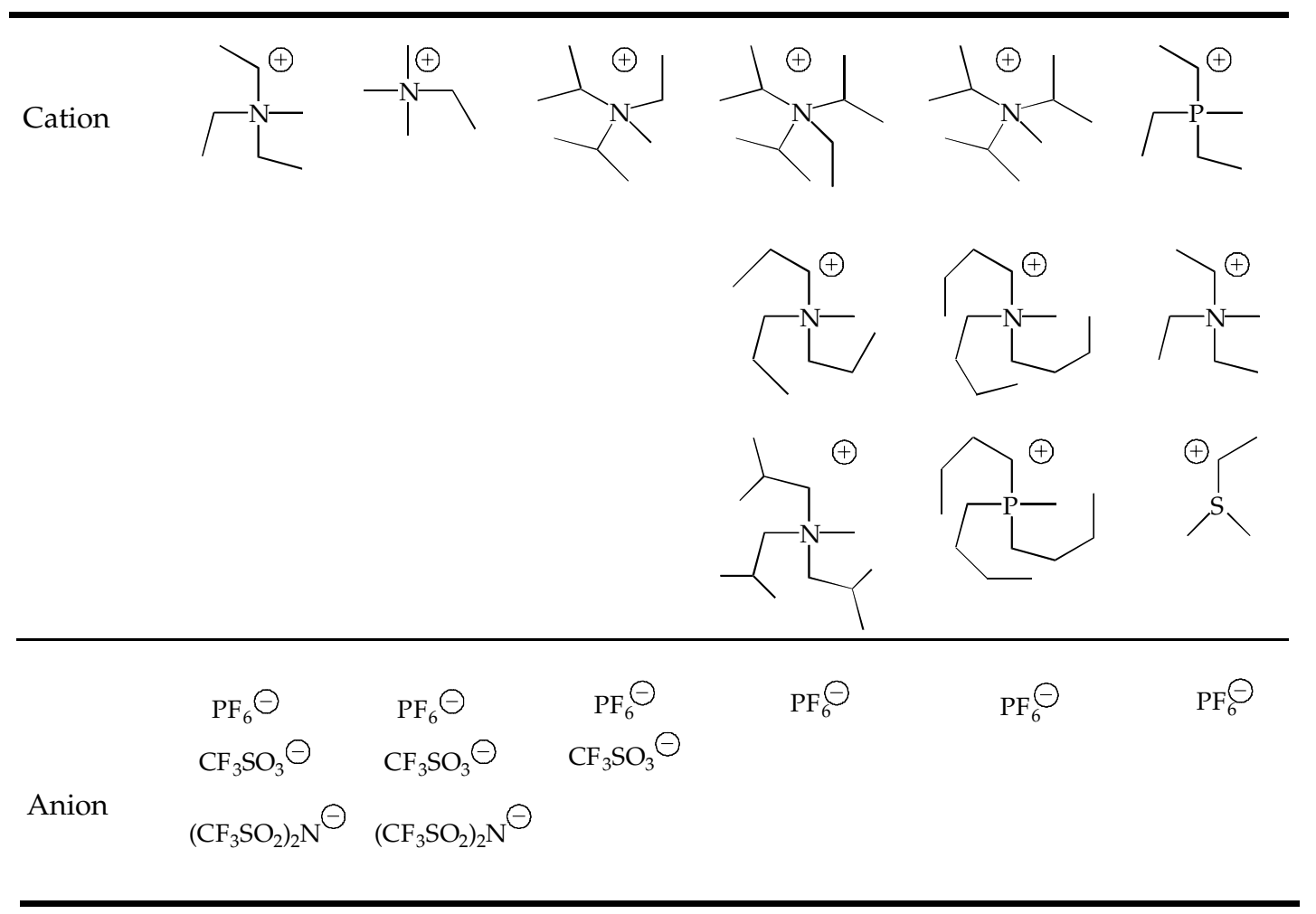




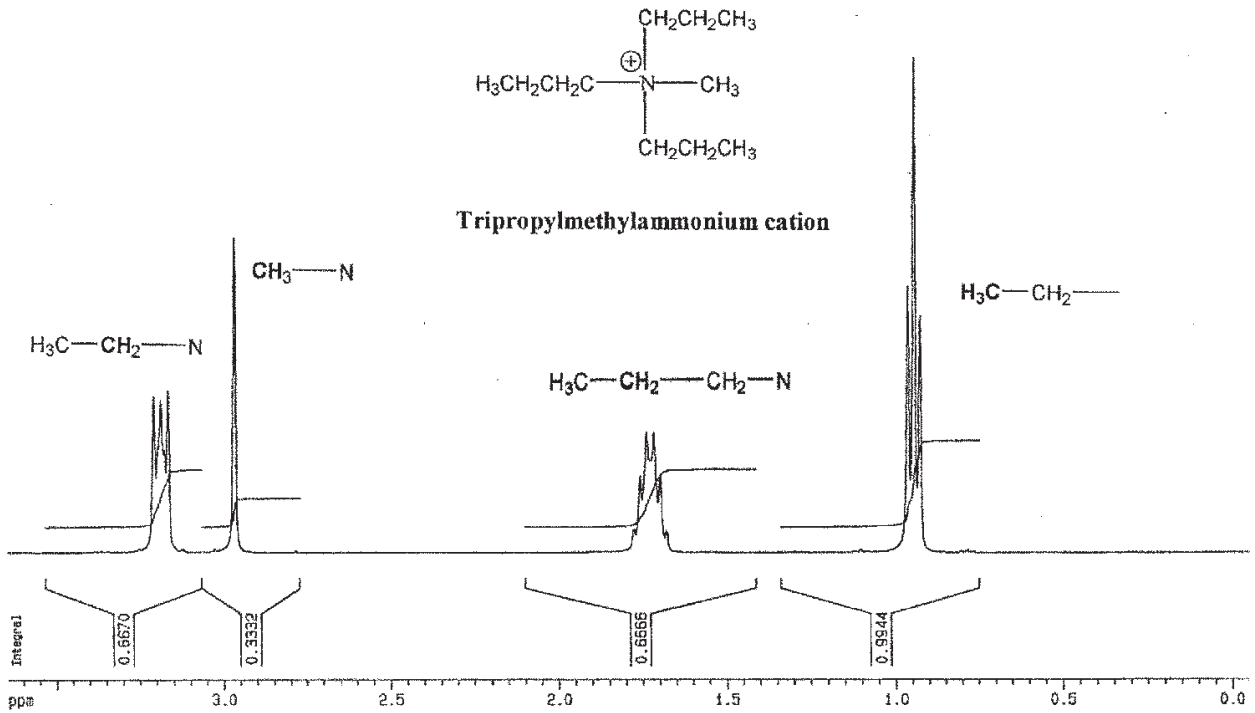

Figure 2.1: NMR spectra of tripropylmethylammonium cation.

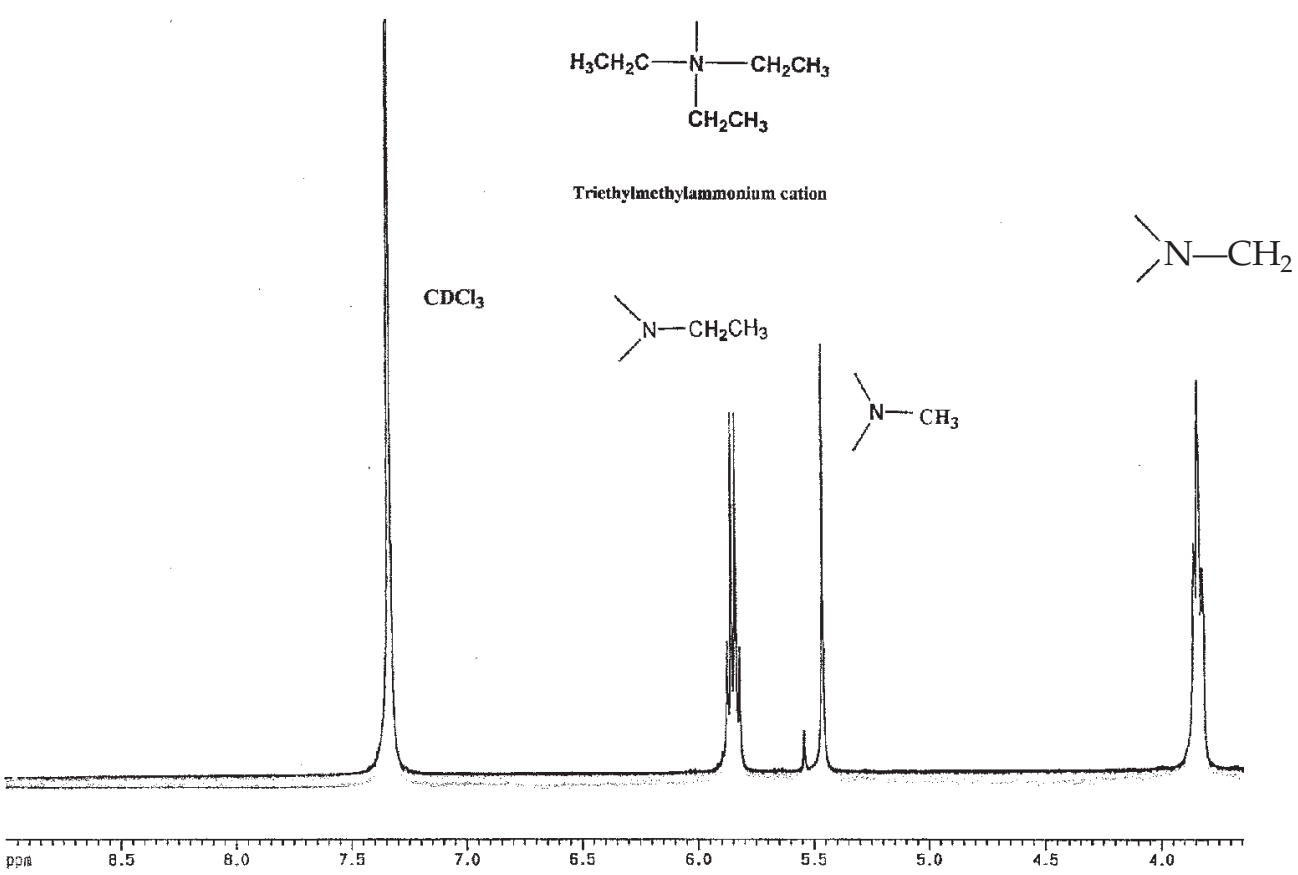

Figure 2.2: NMR spectra of triethylmethylammonium cation. 


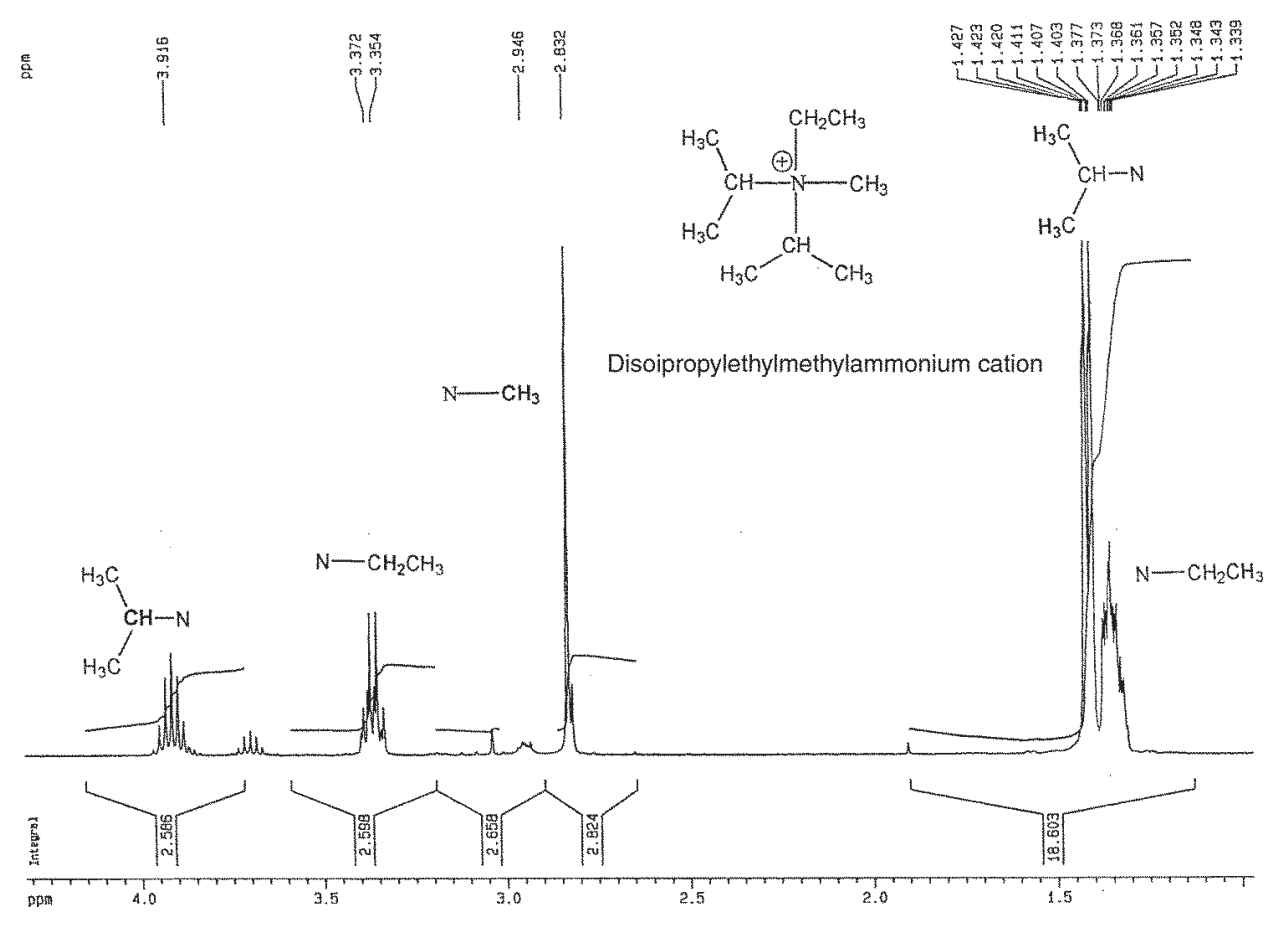

Figure 2.3: NMR spectra of diisopropylethylmethylammonium cation.

More importantly, the absence of other nuclear signals than the expected ones and the low, clean noise level also indicate the high purity of these salts. This corroborates the purity control achieved by repetitive recrystallization. For example, figure 2.1 shows the NMR spectra of a tripropylmethylammonium cation. The chemical shifts for $\mathrm{N}$-adjacent protons are typically between $3 \sim 4$ ppm, with a distinct splitting pattern of $\mathrm{CH}_{3}-\mathrm{CH}_{2}-\mathrm{CH}_{2}-\mathrm{N}$ as in propyl as well as a singular peak of $\mathrm{CH}_{3}-\mathrm{N}$. The integration under those peaks confirms the ratio of proton numbers corresponding to each alkyl group. This is a positive identification for the expected compound with high quality.

Figure 2.2 shows the NMR spectra of triethylmethylammonium cation. Likewise, $\mathrm{CH}_{3} \mathrm{CH}_{2}-\mathrm{N}$ and $\mathrm{CH}_{3}-\mathrm{N}$ were identified by chemical shifts, peak integration, and the splitting pattern within ethyl. (An error in chemical shift labeling was made by the operator when the spectrum was plotted. The solvent used in this case is $\mathrm{D}_{2} \mathrm{O}$ instead of $\mathrm{CDCl}$, so the authentic chemical shift referred to the standard should be the labeling value minus 2.8.)

Figure 2.3 shows the NMR spectra of diisopropylethylmethylammonium cation. The conspicuous splitting pattern for isopropyl is obvious in the multiplets at $4.0 \mathrm{ppm}$, along with the clear $\mathrm{CH}_{3}-\mathrm{N}$ and $\mathrm{CH}_{3} \mathrm{CH}_{2}-\mathrm{N}$ already seen in figures 2.1 and 2.2. The more complicated pattern in $\mathrm{CH}_{3} \mathrm{CH}_{2}-\mathrm{N}$ at $1.35 \mathrm{ppm}$ is caused by the coupling effects from the sterically adjacent protons in isopropyl. This is expected because the bulky isopropyls crowd the space around the central N. 


\section{Experimental}

\subsection{Materials Preparation}

The $\mathrm{Et}_{4} \mathrm{NPF}_{6}$ and the $\mathrm{Et}_{4} \mathrm{NBF}_{4}$ salts of $99 \%$ purity were obtained from Aldrich and used without further purification. The asymmetric quaternary ammonium salts were prepared using the methods described in section 2 (Synthesis of New Asymmetric Quaternary Ammonium Salts). They were purified by triple recrystallization in methanol and then vacuum dried at 80 ${ }^{\circ} \mathrm{C}$ before use.

The solvents EC, DMC, and PC, were obtained from Grant Chemicals in electrochemical grade and further distilled before use. AN obtained from Aldrich was distilled before use. the ethylmethyl sulfone (EMSF) was synthesized in our laboratory. The physical properties of the solvents selected for our studies are listed in table 3.1. All solvents used in the fabrication of electrolytes were dried and redistilled.

Activated carbon (M series) from Osaka Gas was used without further treatment. The carbon electrode was prepared from 95 parts of activated carbon of various brands and 5 parts of Teflon as binder. The resultant mixture was dispersed thoroughly in an appropriate solvent. Then the solution was either evaporated to make an activated carbon-based paste, or directly coated onto an aluminum (Al) substrate by spraying. Typically the electrodes were cut into an area of $\sim 100 \mathrm{~cm}^{2}$, with a loading of $\sim 2.8 \mathrm{mg} / \mathrm{cm}^{2}$. The prepared electrodes were vigorously dried under vacuum.

We used different commercial separators, including Celgard ${ }^{\circledR}$ series films.

Table 3.1: Physical properties of selected solvents.

\begin{tabular}{|c|c|c|c|c|c|}
\hline Solvent & $\varepsilon$ & $\begin{array}{c}\eta \\
(\mathrm{cP})\end{array}$ & $\begin{array}{l}\mathrm{mp} \\
\left({ }^{\circ} \mathrm{C}\right)\end{array}$ & $\begin{array}{l}\mathrm{bp} \\
\left({ }^{\circ} \mathrm{C}\right)\end{array}$ & MW \\
\hline Ethylene carbonate (EC) & 95 & 1.85 & 35 & 244 & 88 \\
\hline Propylene carbonate (PC) & 65 & 2.53 & -49 & 242 & 102 \\
\hline Acetonitrile (AN) & 36 & 0.343 & -49 & 82 & 41 \\
\hline$\gamma$-Butyrolactone (BL) & 42 & 1.73 & -43 & 204 & 86 \\
\hline Glutaronitrile (GLN) & 37 & 5.3 & -29 & 286 & 94 \\
\hline N, N-dimethylformamide (DMF) & 37 & 0.79 & -61 & 153 & 73 \\
\hline Sulfolane (SL) & 43 & 10 & 28 & 287 & 120 \\
\hline Diethyl carbonate (DEC) & 2.82 & 0.748 & -43 & 126 & 119 \\
\hline Dimethyl carbonate (DMC) & 3.12 & 0.585 & 4.6 & 91 & 90 \\
\hline Ethylmethyl carbonate (EMC) & 2.9 & 0.65 & -55 & 107 & 104 \\
\hline Toluene (TL) & 2.38 & 0.59 & -95 & 110.6 & 92 \\
\hline $\begin{array}{l}\text { Key } \\
\varepsilon=\text { dialectric constant } \\
\eta=\text { viscosity } \\
\text { mp = meling point } \\
\text { bp = boiling point } \\
\text { MW = molecular weight }\end{array}$ & & & & & \\
\hline
\end{tabular}




\subsection{Measurements}

\section{Melting Point (or Decomposition Temperatures) and Solubility}

We used a Perkin-Elmer Differential Scanning Calorimetry (DSC) 7 to determine the melting point of the salts. The salt samples were sealed in aluminum sample pans under pure argon. Typically, we conducted the experiments under a helium atmosphere at a heating rate of $5{ }^{\circ} \mathrm{C}$. We defined the point of the onset of melting as the melting point. We visually determined the solubility of the salts. To determine the solubility, a salt was slowly and continually dissolved in a specific amount of solvent until a solid residue remained that was stable against either shaking or shelving.

\section{Electrical Conductivity}

For electrolytic and molar conductivity measurements, samples of electrolytes were placed inside conductivity cells under argon. These cells were dip-type with cell constants near $0.1 \mathrm{~cm}^{-1}$ and sealable through a ground-glass opening on a filling tube connected to the cell body. Sample temperatures were kept constant during a measurement with a Tenney Engineering environmental chamber capable of both heating and cooling. We determined the solution's bulk resistance with impedance spectroscopy; we could then derive and conductivity from the cell geometry, which comprised a pair of parallel platinum electrodes. An HP 4284A precision LRC meter was used for the measurement. Densities of the electrolytes were measured with a Mettler-Toledo DA-110M density meter at room temperature.

\section{Electrochemical Stability Window}

The electrochemical stability window $(\Delta V)$ of the electrolyte was determined by measuring the limiting reduction $\left(E_{r e d}\right)$ and oxidation potentials $\left(E_{o x}\right)$ of the electrolyte against a glassy carbon working electrode with a diameter of $0.32 \mathrm{~cm}$. These limiting potentials were measured by a linear sweep voltammetry technique using an EG\&G 273 Potentiostat/Galvanostat controlled by a computer. A three-electrode configuration cell was employed, with glassy carbon as the working electrode, $\mathrm{Li}$ as the reference electrode, and platinum $(\mathrm{Pt})$ as the counter electrode. Nickel (Ni) wire was also used as a reference electrode in some studies in which the electrolyte contained $\mathrm{BF}_{4}{ }^{-}$and $\mathrm{PF}_{6}{ }^{-}$anions. Large area Pt gauze was used as a counter electrode. The measurement was done in an argon-filled dry box. Typically, the scan rate was $5 \mathrm{mV} / \mathrm{s}$, and $100 \mu \mathrm{A} / \mathrm{cm}^{2}$ was used as the cutoff current density for the stability window limit. To evaluate $E_{r e d}$ and $E_{o x}$ of the electrolytes against porous activated carbon electrodes instead of the nonporous glassy carbon electrodes, we had to use a different method. This new method will be discussed in section 4.3 .

\section{Cell Testing}

The assembled cell was subjected to a charge/discharge test on an EG\&G 273 Potentiostat/Galvanostat. Typically, we used a charge/discharge rate of $1.0 \mathrm{~mA} / \mathrm{cm}^{2}$. 
Table 3.2: Estimated ionic radii ( $r)$, molecular weight (MW), and single ion-limiting conductivity $\left(\lambda_{0}\right)$.

\begin{tabular}{lcccc}
\hline Ion & $\begin{array}{c}r \\
(\mathrm{~nm})\end{array}$ & $\mathrm{MW}$ & $\begin{array}{c}\lambda_{\mathrm{o}} \\
\text { in PC } \\
\text { at } 25^{\circ} \mathrm{C} \\
\left(\mathrm{S} \mathrm{cm}^{2} \mathrm{~mol}^{-1}\right)\end{array}$ & $\begin{array}{c}\lambda_{\mathrm{o}} \\
\text { in } \gamma-\mathrm{BL} \\
\text { at } 25^{\circ} \mathrm{C} \\
\left(\mathrm{S} \mathrm{cm}^{2} \mathrm{~mol}^{-1}\right)\end{array}$ \\
\hline $\mathrm{Li}^{+}$ & 0.076 & 6.94 & 8.43 & 13.99 \\
$\mathrm{Me}_{4} \mathrm{~N}^{+}$ & 0.283 & 74.147 & 14.50 & 21.52 \\
$\mathrm{Me}_{3} \mathrm{EtN}^{+}$ & 0.298 & 88.174 & 14.14 & 20.77 \\
$\mathrm{Me}_{2} \mathrm{Et}_{2} \mathrm{~N}^{+}$ & 0.313 & 102.201 & 13.90 & 20.18 \\
$\mathrm{MeEt}_{3} \mathrm{~N}^{+}$ & 0.327 & 116.228 & 13.68 & 19.70 \\
$\mathrm{Et}_{4} \mathrm{~N}^{+}$ & 0.343 & 103.255 & 13.50 & 19.32 \\
$\mathrm{Pr}_{4} \mathrm{~N}^{+}$ & 0.381 & 186.359 & - & - \\
$\mathrm{Bu}_{4} \mathrm{~N}^{+}$ & 0.415 & 242.467 & 9.09 & 14.03 \\
$\mathrm{ClO}_{4}^{-}$ & 0.237 & 99.449 & 18.93 & 28.45 \\
$\mathrm{BF}_{4}^{-}$ & 0.229 & 86.802 & 20.43 & 30.77 \\
$\mathrm{PF}_{6}{ }^{-}$ & 0.254 & 144.964 & 19.86 & 26.70 \\
$\mathrm{AsF}_{6}^{-}$ & 0.260 & 188.912 & 17.58 & 25.92 \\
$\mathrm{CF}_{3} \mathrm{SO}_{3}^{-}$ & 0.270 & 149.063 & 16.89 & 24.93 \\
$\left(\mathrm{CF}_{3} \mathrm{SO}_{2}\right)_{2} \mathrm{~N}^{-}$ & 0.325 & 280.135 & 14.40 & 20.55 \\
$\mathrm{C}_{4} \mathrm{~F}_{9} \mathrm{SO}_{3}^{-}$ & 0.339 & 299.087 & 13.03 & 18.66 \\
$\mathrm{BPh}_{4}^{-}$ & 0.419 & 319.232 & 8.52 & 11.52 \\
\hline
\end{tabular}




\section{Results and Discussion}

\subsection{Melting Point and Solubility}

The increase in solubility as a result of a symmetry change in the cation structure is quite interesting. When the salt contains a cation with an asymmetric structure, we found that the solubility of the salt increases with increasing cation size (or cation molecular weight).

Results of the measurements on solubility and melting behavior of $\mathrm{Et}_{4} \mathrm{NPF}_{6}$ and $\mathrm{Et}_{3} \mathrm{MeNPF}_{6}$ salts are summarized in table 4.1 (25), along with the structure and symmetricity of their cations. The solubility of $\mathrm{Et}_{4} \mathrm{NPF}_{6}$, in which the cation is symmetric, in EC-DMC was found to be $1.4 \mathrm{M}$ at room temperature. The solubility of $\mathrm{Et}_{3} \mathrm{MeNPF}_{6}$, in which the cation is asymmetric, in EC-DMC was 2.2 M. For two salts that differ in their cations by only one methyl group in one constituent among four around the central nitrogen, the differences in solubility and melting behavior are strikingly large $(1.4 \mathrm{M}$ vs. $2.2 \mathrm{M})$. Since the most obvious change in going from the first salt to the second is from the symmetric cation $\mathrm{Et}_{4} \mathrm{~N}^{+}$to the unsymmetric cation $\mathrm{Et}_{3} \mathrm{MeN}^{+}$, it is reasonable to consider this symmetricity change as the primary cause for the differences in solubility and melting behavior of the two salts. We believe that by affecting the lattice energy of a salt, this change of cationic symmetricity causes the change in the salt's properties.

The lattice energy of an ionic solid comes primarily from the electrostatic attraction between the cations and the anions that form the solid. Its magnitude is inversely proportional to the average distance between the ions (26). In the formation of the ionic salt $\mathrm{Et}_{4} \mathrm{NPF}_{6}$, the $\mathrm{Et}_{4} \mathrm{~N}^{+}$cations, owing to their symmetric shape, allow more efficient packing with $\mathrm{PF}_{6}{ }^{-}$anions than $\mathrm{Et}_{3} \mathrm{MeN}^{+}$cations in the formation of $\mathrm{Et}_{3} \mathrm{MeNPF}_{6}$ salt. This packing results in a shorter average distance between the symmetric cations and the anions, giving $\mathrm{Et}_{4} \mathrm{NPF}_{6}$ a stronger lattice that is more difficult to break apart. When this breaking apart is attempted through thermal agitation, such as through heating in the DSC experiment, the stronger lattice of the salt manifests itself with a decomposition temperature that is $129^{\circ} \mathrm{C}$ higher than the melting point of $\mathrm{Et}_{3} \mathrm{MeNPF}_{6}$ salt. When it is attempted through solvation by polar solvent molecules, such as

Table 4.1: Comparison of $\mathrm{Et}_{4} \mathrm{NPF}_{6}$ and $\mathrm{Et}_{3} \mathrm{MeNPF}_{6}$ salts.

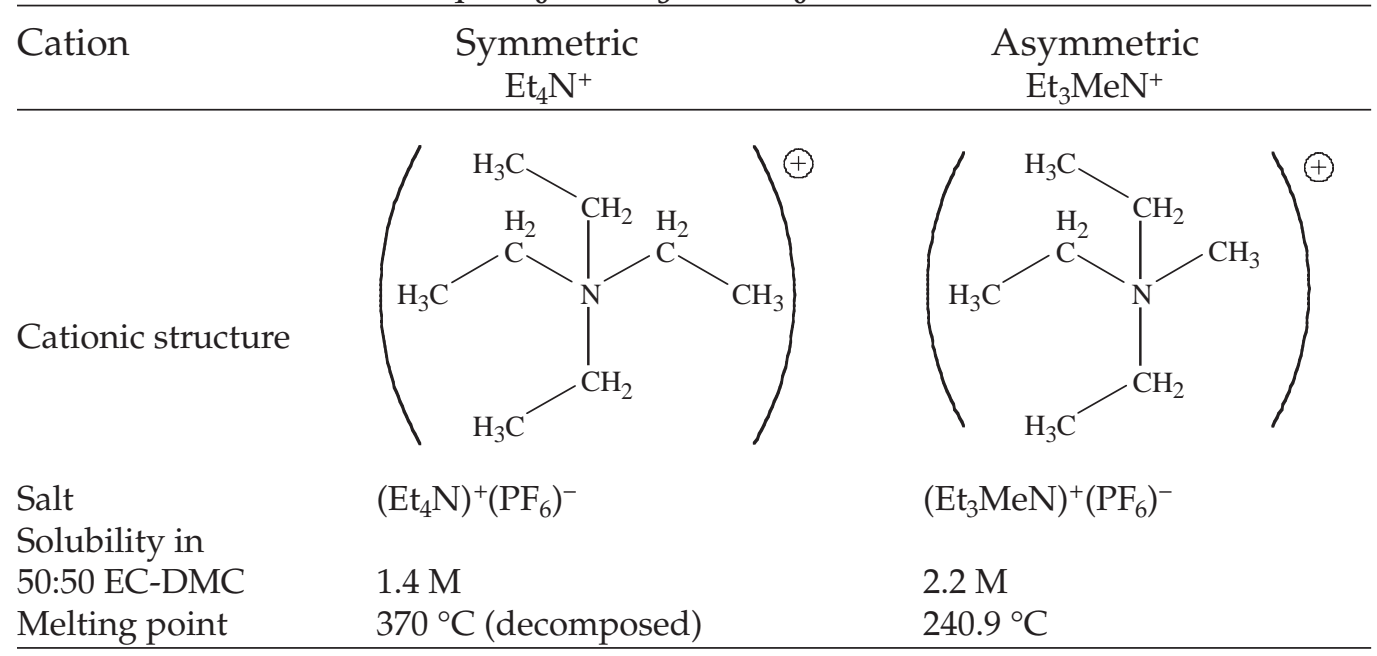


through dissolution in EC-DMC solvent, the stronger lattice again manifests itself with a solubility that is lower than that of $\mathrm{Et}_{3} \mathrm{MeNPF}_{6}$ by more than one-third in the units of molarity.

The same type of correlation between melting point and solubility has been observed for a series of tetraalkylammonium salts of the form $\mathrm{R}_{1} \mathrm{R}^{\prime \prime}{ }_{3} \mathrm{NPF}_{6}$, where $\mathrm{R}^{\prime}$ and $\mathrm{R}^{\prime \prime}$ represent two different alkyl groups and their subscripts indicate that the cations have the same symmetricity (25). As shown in figure 4.1, we observed that the melting point of the salt that contains an asymmetric cation decreases with an increase in the cation size (27).

It is important to note that if $\mathrm{Et}_{4} \mathrm{NPF}_{6}$ salt was arranged in the above series according to the size of its cation, its melting point would be lower than that of $\mathrm{Et}_{3} \mathrm{MeNPF}_{6}$ salt. Instead, the lattice of $\mathrm{Et}_{4} \mathrm{NPF}_{6}$ salt, due to the symmetric shape of its $\mathrm{Et}_{4} \mathrm{~N}^{+}$cation, persists to a much higher temperature than that of $\mathrm{Et}_{3} \mathrm{MeNPF}_{6}$ salt. This indicates that, in addition to its size, the symmetry of an ion in a salt can affect the melting point or the lattice energy of a salt.

This effect, however, only occurs when the size difference is not too great. EtMe $\mathrm{NPF}_{6}$ salt, for example, its cation being asymmetric but much smaller than $\mathrm{Et}_{4} \mathrm{~N}^{+}$, decomposes at $389.1{ }^{\circ} \mathrm{C}$, $19^{\circ} \mathrm{C}$ higher than $\mathrm{Et}_{4} \mathrm{NPF}_{6}$ salt (25). When the asymmetric alkylammonium cation is combined with a larger anion such as $\mathrm{Tf}^{-}$and $\mathrm{Im}^{-}$, the solubility in EC-DMC is increased to 3.1 and $2.7 \mathrm{M}$, respectively, versus $2.2 \mathrm{M}$ for a smaller $\mathrm{PF}^{-}$anion, as shown in figure 4.2 (27).
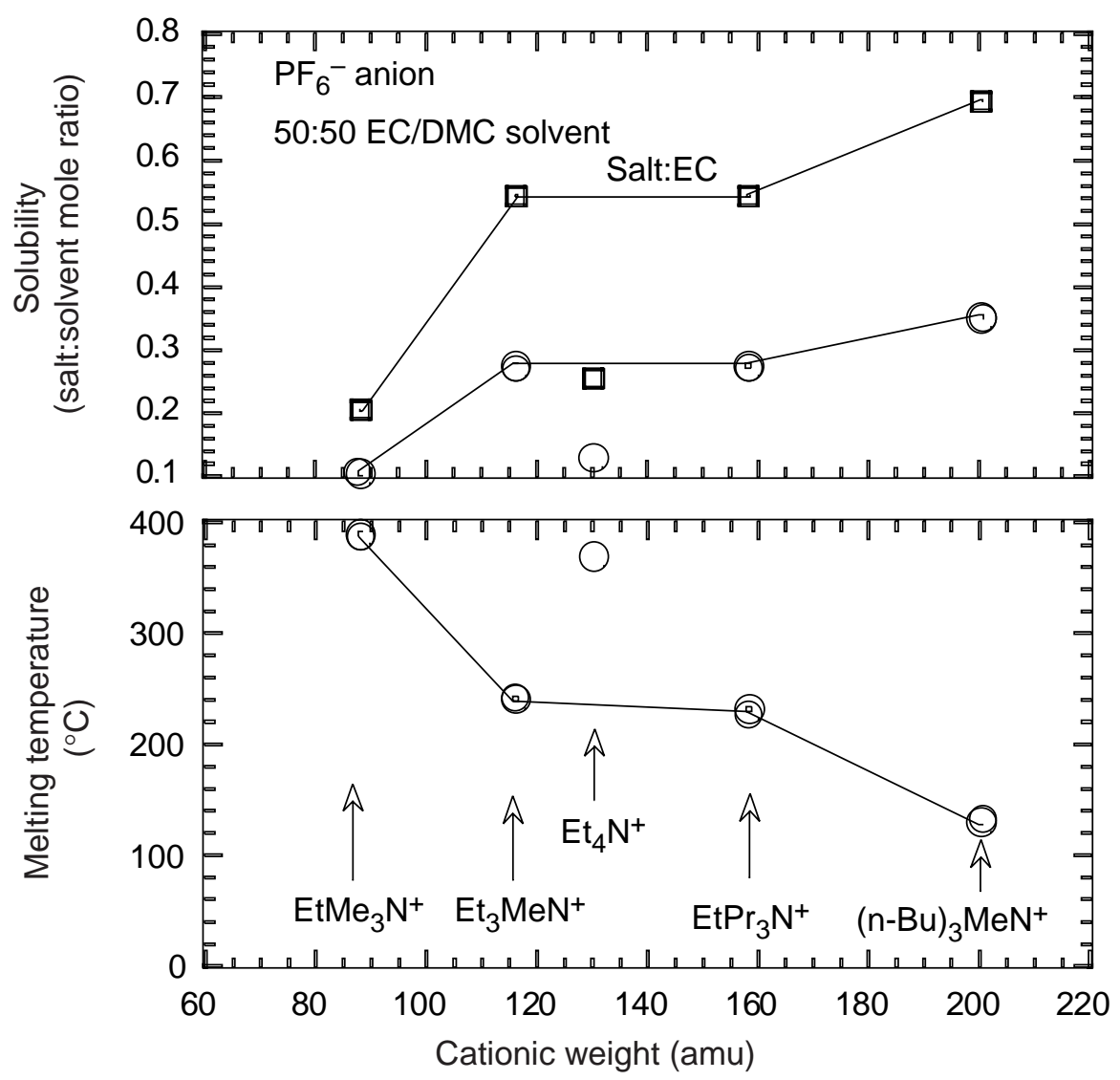

Figure 4.1: The correlation of melting point and solubility of asymmetry quaternary ammonium salts (in 50:50 EC-DMC) with variations in cation. Commercially available $\mathrm{Et}_{4} \mathrm{NPF}_{6}$ is used as a control. 


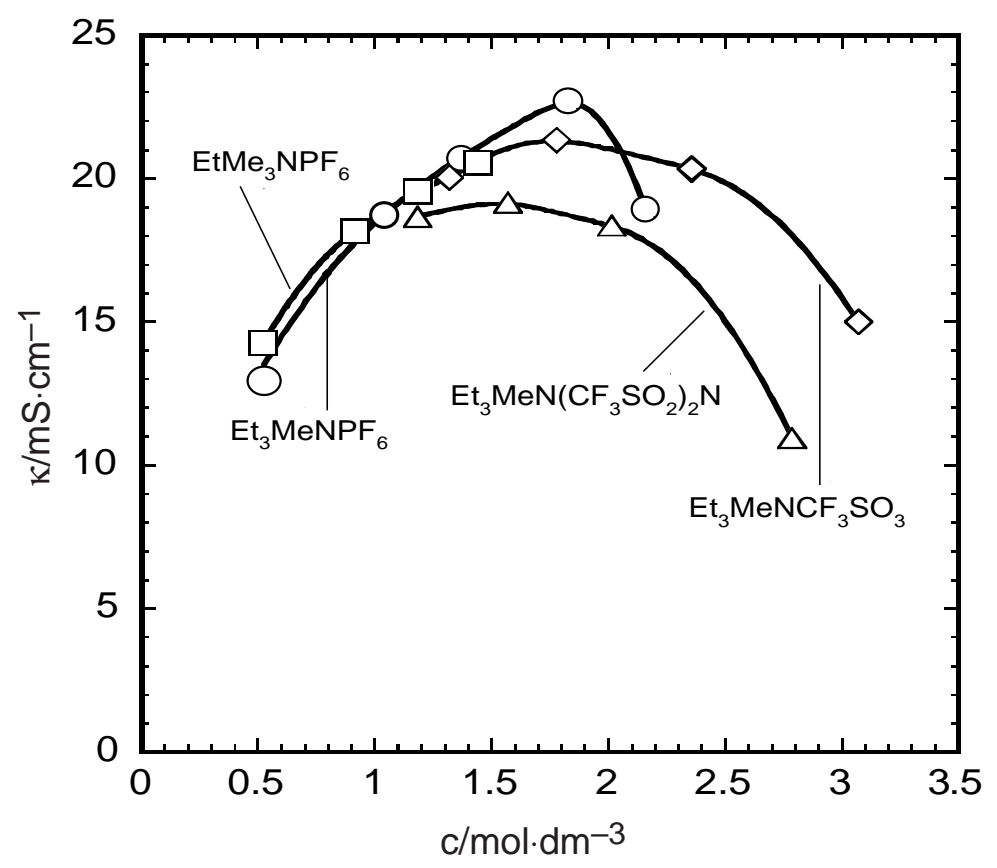

Figure 4.2: Room temperature electrolytic conductivities of EC-DMC (50:50 by wt.) solutions of asymmetric quaternary ammonium salts at different salt concentrations.

\subsection{Conducitvity}

\section{Conductivity of Electrolytes Containing $\mathrm{Et}_{4} \mathrm{NBF}_{4}$ and $\mathrm{Et}_{4} \mathrm{NPF}_{6}$}

The conductivities of the electrolytes containing the commercially available quaternary ammonium salt $\mathrm{Et}_{4} \mathrm{NBF}_{4}$ in various solvent systems at a concentration of $0.65 \mathrm{M}$ and at the saturated concentration at room temperature are listed in table 4.2. The conductivities of these electrolytes as a function of temperature from -40 to $70{ }^{\circ} \mathrm{C}$ are shown in figure 4.3 .

We note from table 4.2.1 that both the conductivity and the salt concentration are higher for $\mathrm{Et}_{4} \mathrm{NBF}_{4}$ in $\mathrm{AN}, \mathrm{BL}$, and $\mathrm{EC}$ than in PC. Most notably, $\mathrm{EC}$ can dissolve $\mathrm{Et}_{4} \mathrm{NBF}_{4}$ up to $1.62 \mathrm{M}$ and shows a conductivity of $19.12 \mathrm{mS} / \mathrm{cm}$ at room temperature. AN can dissolve $1.68 \mathrm{M}$ $\mathrm{Et}_{4} \mathrm{NBF}_{4}$ and its conductivity reaches as high as $57.21 \mathrm{mS} / \mathrm{cm}$. With the addition of EC to PC, both the conductivity and the salt concentration are increased. With the further addition of a low dielectric constant and low viscosity solvent such as DMC and TL, the conductivity is further increased but not the concentration.

The conductivity of $\mathrm{Et}_{4} \mathrm{NBF}_{4}$ in PC-EC as a function of concentration is shown in figure 4.4. The conductivity reaches its highest value of $13.8 \mathrm{mS} / \mathrm{cm}$ at a concentration of about $1.4 \mathrm{M}$.

\section{Conductivity of Electrolytes Containing Asymmetric Quaternary Ammonium Salts}

Results of conductivity measurements on the two sets of concentrated electrolytes are plotted in figure 4.4 for $\mathrm{Et}_{4} \mathrm{NPF}_{6}$ (a) and $\mathrm{Et}_{3} \mathrm{MeNPF}_{6}$ (b) in 50:50 EC-DMC solvent. The solubility of $\mathrm{Et}_{3} \mathrm{MeNPF}_{6}$ salt is higher than that of $\mathrm{Et}_{4} \mathrm{NPF}_{6}$ salt in EC-DMC. However, their conductivity values are almost identical at the same concentrations. This is shown in a replotted, combined 
Table 4.2: Conductivities of electrolytes containing $\mathrm{Et}_{4} \mathrm{NBF}_{4}$ in various solvent systems at a concentration of $0.65 \mathrm{M}$ and at the saturated concentration.

\begin{tabular}{|c|c|c|c|}
\hline $\begin{array}{l}\text { Solvent system } \\
\text { (ratio } \\
\text { by wt.) }\end{array}$ & $\begin{array}{c}\text { Saturated } \\
\text { concentration } \\
\text { (c), M }\end{array}$ & $\begin{array}{c}\sigma \text { at } c(\mathrm{M}) \\
\mathrm{mS} / \mathrm{cm}\left(20^{\circ} \mathrm{C}\right)\end{array}$ & $\begin{array}{l}\sigma_{\max } \text { at } c(\mathrm{M} / \mathrm{L}), \\
\mathrm{mS} / \mathrm{cm}\left(20^{\circ} \mathrm{C}\right)\end{array}$ \\
\hline AN & 1.68 & $43 @ 0.65$ M/1 & $57.21 @ 1.68 \mathrm{M} / \mathrm{L}$ \\
\hline AN/EC $(15 / 85)$ & 1.65 & $17.89 @ 0.65$ M/L & $27.26 @ 1.65 \mathrm{M} / \mathrm{L}$ \\
\hline AN/EC $(50 / 50)$ & & $35.47 @ 0.843$ M/L & \\
\hline AN/PC $(15 / 85)$ & 1.14 & $15.58 @ 0.65$ M/L & $20.51 @ 1.14$ M/L \\
\hline AN/PC $(50 / 50)$ & & $27.93 @ 0.65$ M/L & \\
\hline AN/TL $(50 / 50)$ & 0.80 & $24.2 @ 0.61$ M/L & $25.8 @ 0.80 \mathrm{M} / \mathrm{L}$ \\
\hline BL & 1.18 & $13.4 @ 0.65 \mathrm{M} / \mathrm{L}$ & $16.9 @ 1.18 \mathrm{M} / \mathrm{L}$ \\
\hline BL/EC (50/50) & & $12.97 @ 0.65$ M/L & \\
\hline BL/TL (50/50) & 0.49 & $9.04 @ 0.49$ M/L & $9.04 @ 0.49$ M/L \\
\hline PC & 0.86 & $8.8 @ 0.65 \mathrm{M} / \mathrm{L}$ & $12.44 @ 0.86 \mathrm{M} / \mathrm{L}$ \\
\hline PC/EC (50/50) & 1.311 & $11.03 @ 0.65$ M/L & $15.98 @ 1.311$ M/L \\
\hline $\mathrm{PC} / \mathrm{EC} / \mathrm{AN}$ & & & \\
\hline$(42.5 / 42.5 / 15)$ & 1.37 & $16.78 @ 0.65 \mathrm{M} / \mathrm{L}$ & $23.97 @ 1.37 \mathrm{M} / \mathrm{L}$ \\
\hline $\mathrm{PC} / \mathrm{EC} / \mathrm{DMC}$ & & & \\
\hline$(42.5 / 42.5 / 15)$ & 1.19 & $12.36 @ 0.65$ M/L & $17.46 @ 1.19$ M/L \\
\hline $\mathrm{PC} / \mathrm{EC} / \mathrm{MF}$ & & & \\
\hline $\begin{array}{l}(42.5 / 42.5 / 15) \\
\mathrm{PC} / \mathrm{EC} / \mathrm{TL}\end{array}$ & 1.19 & 15.15 @0.65 M/L & $20.39 @ 1.19$ M/L \\
\hline$(42.5 / 42.5 / 15)$ & & $13.85 @ 0.65$ M/kg & \\
\hline $\mathrm{AC}$ & 0.30 & $13.85 @ 0.30$ M/L & $13.85 @ 0.30 \mathrm{M} / \mathrm{L}$ \\
\hline $\mathrm{EC}$ & 1.625 & $19.12 @ 1.625 \mathrm{M} / \mathrm{L}^{\mathrm{a}}$ & $19.12 @ 1.625 \mathrm{M} / \mathrm{L}^{\mathrm{a}}$ \\
\hline
\end{tabular}

Key

$\mathrm{AC}=$ acetone

$\mathrm{AN}=$ acetonitrile

$\mathrm{BL}=\gamma$-butyrolactone

$\mathrm{DMC}=$ dimethyl carbonate

$\mathrm{EC}=$ ethylene carbonate

$\mathrm{MF}=$ methyl formate

$\mathrm{PC}=$ propylene carbonate

$\mathrm{TL}=$ toluene

aThe lowest concentration at which both EC and the salt could be mutually dissolved is $1.24 \mathrm{M} / \mathrm{L}$.

form in figure 4.5 for ease of comparison. The measured conductivity values (dots) are connected by polynomial curves fitted to the values. Peak conductivities and the corresponding concentrations are evaluated from the polynomial curves and represented in the figures by the crosses and the curves connecting them. It can be seen from these figures that the conductivities of both electrolytes reach their maximum at different concentrations, depending on the type of salt and the temperature. The higher the temperature, the higher are the conductivities and the peak-conductivity concentrations. Furthermore, the peaks of $\mathrm{Et}_{3} \mathrm{MeNPF}_{6}$ electrolytes occur at concentrations substantially higher than those of $\mathrm{Et}_{4} \mathrm{NPF}_{6}$ electrolytes. On the other hand, the conductivity values of these two electrolytes almost overlap at all concentrations except those near and above peak-conductivity concentrations. 


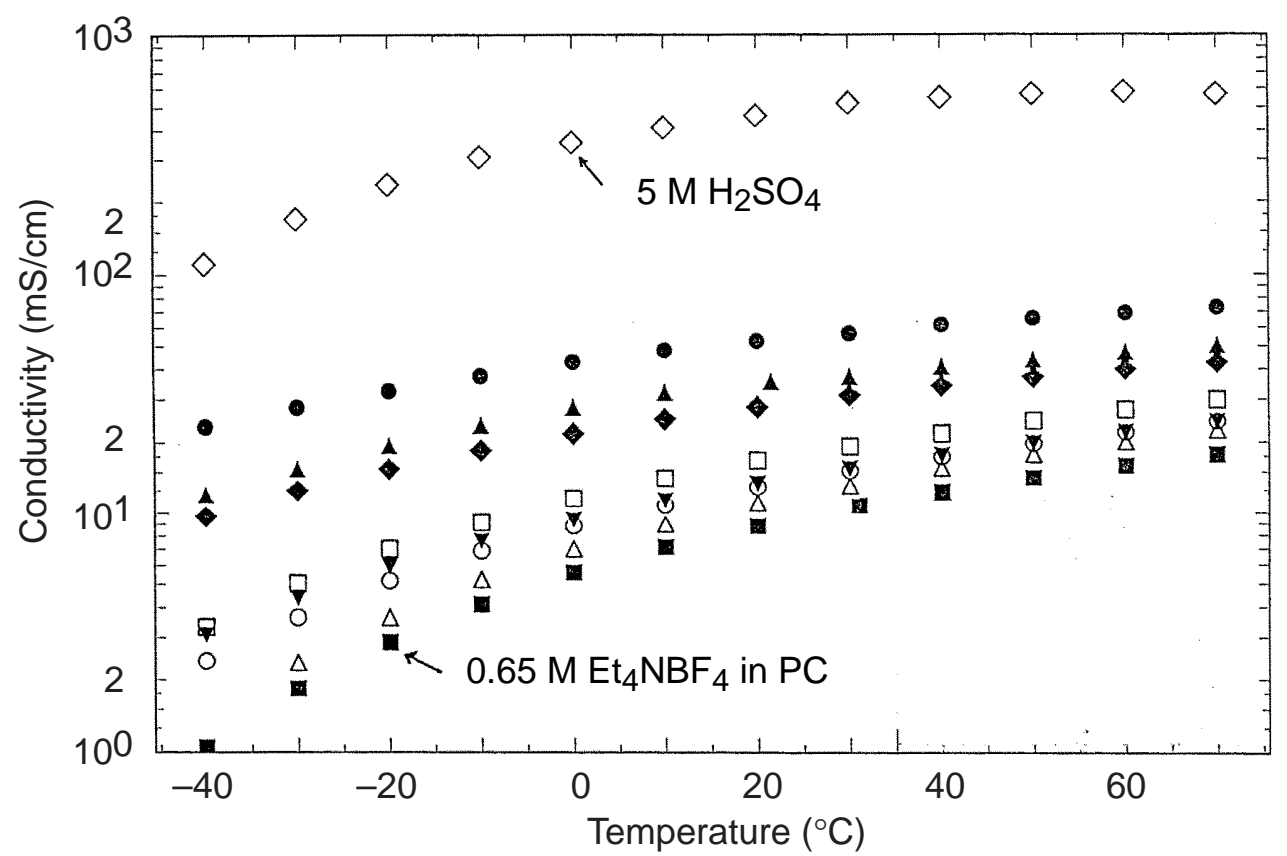

Figure 4.3: Conductivity vs. temperature from -40 to $70{ }^{\circ} \mathrm{C}$ for electrolytes containing $0.65 \mathrm{M} \mathrm{Et}_{4} \mathrm{NBF}_{4}$ in various solvent systems. $\left(\nabla: 10 \mathrm{~N} \mathrm{H}_{2} \mathrm{SO}_{4}\right.$ solution, $0: 0.87 \mathrm{M} \mathrm{Et}_{4} \mathrm{NBF}_{4}$ in $\mathrm{AN}, \triangle$ : $0.84 \mathrm{M} \mathrm{Et}_{4} \mathrm{NBF}_{4}$ in $\mathrm{AN} / \mathrm{EC}$ (50/50 by wt.), $: 0.65 \mathrm{M} \mathrm{Et}_{4} \mathrm{NBF}_{4}$ in AN/PC, $\square: 0.65 \mathrm{M} \mathrm{Et}_{4} \mathrm{NBF}_{4}$ in EC/PC/AN (42.5/ 42.5/15), $\nabla: 0.65 \mathrm{M} \mathrm{Et}_{4} \mathrm{NBF}_{4}$ in $\mathrm{BL}, \mathrm{O}: 0.65 \mathrm{M} \mathrm{Et}_{4} \mathrm{NBF}_{4}$ in BL/EC (50/50), $\Delta: 0.65$ $\mathrm{MEt}_{4} \mathrm{NBF}_{4}$ in EC/PC, $\square: 0.65 \mathrm{M} \mathrm{Et}_{4} \mathrm{NBF}_{4}$ in $\left.\mathrm{PC}\right)$.

(a)

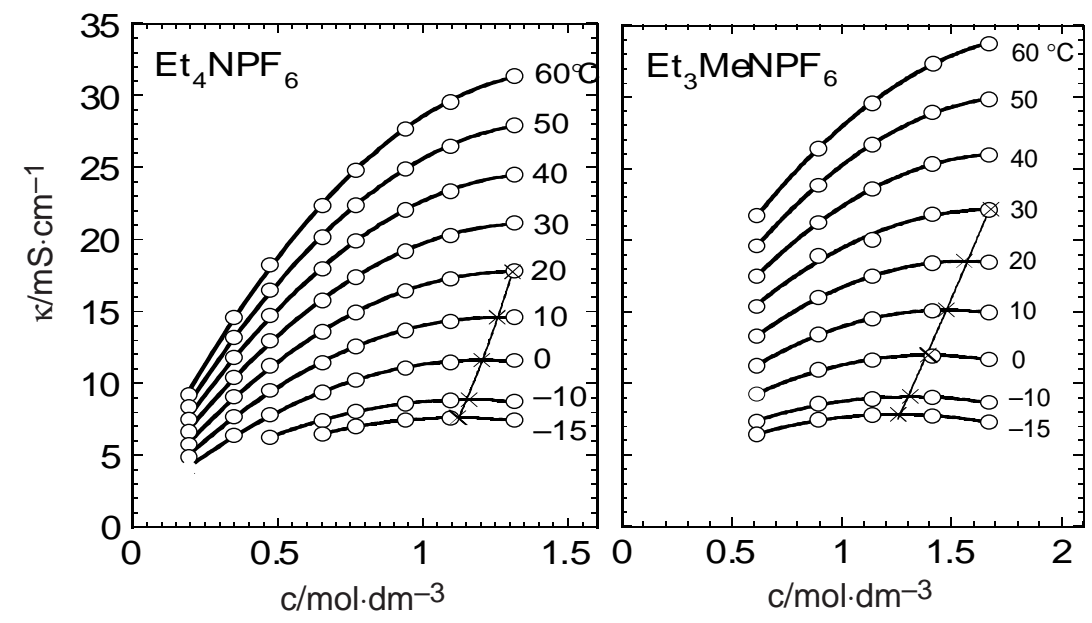

Figure 4.4: Change of electrolytic conductivity with salt concentration for electrolytes $\mathrm{Et}_{4} \mathrm{NPF}_{6}(\mathrm{a})$ and $\mathrm{Et}_{3} \mathrm{MeNPF}_{6}(\mathrm{~b})$ in EC-DMC (50:50) at various temperatures.

The cation size of the quaternary ammonium salts has an impact on the conductivity of the electrolytes. We found that the conductivity decreases with increasing cation size. For example, the conductivity of $1.06 \mathrm{M}(\mathrm{n}-\mathrm{Bu})_{3} \mathrm{MeNPF}_{6}$ with a heavier cation in EC-DMC is lower than that of $1.04 \mathrm{M} \mathrm{Et}_{3} \mathrm{MeNPF}_{6}$ in $\mathrm{EC}-\mathrm{DMC}$, as shown in figure 4.6 (28). 


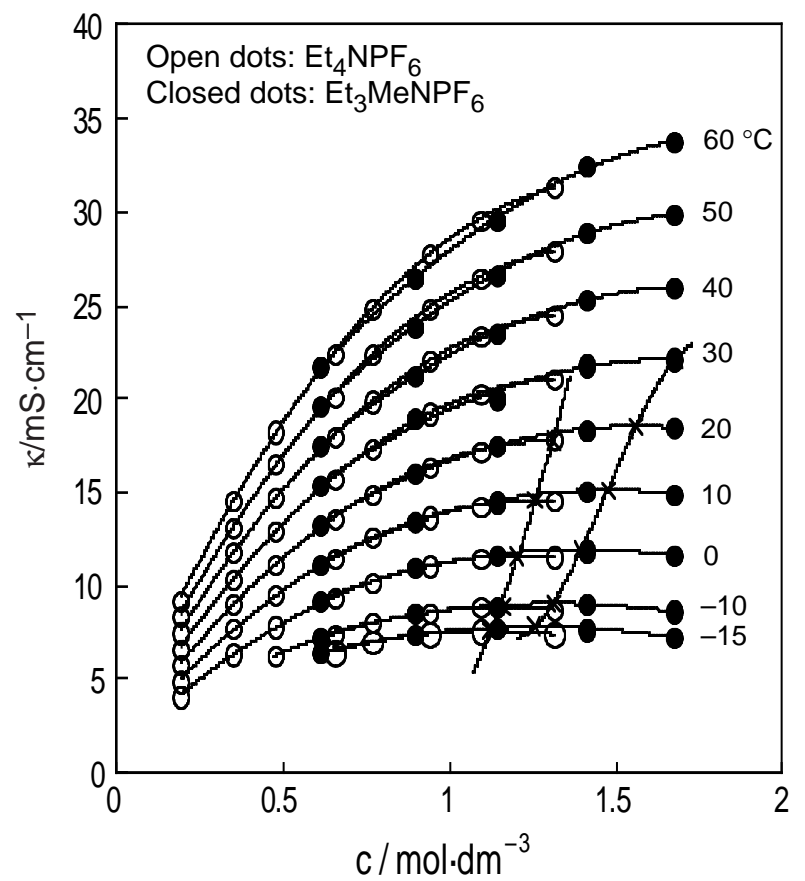

Figure 4.5: Electrolytic conductivity vs. salt concentration at temperatures from -15 to $60^{\circ} \mathrm{C}$ for $\mathrm{Et}_{4} \mathrm{NPF}_{6}$ and $\mathrm{Et}_{3} \mathrm{MeNPF}_{6}$ in EC-DMC (50:50).

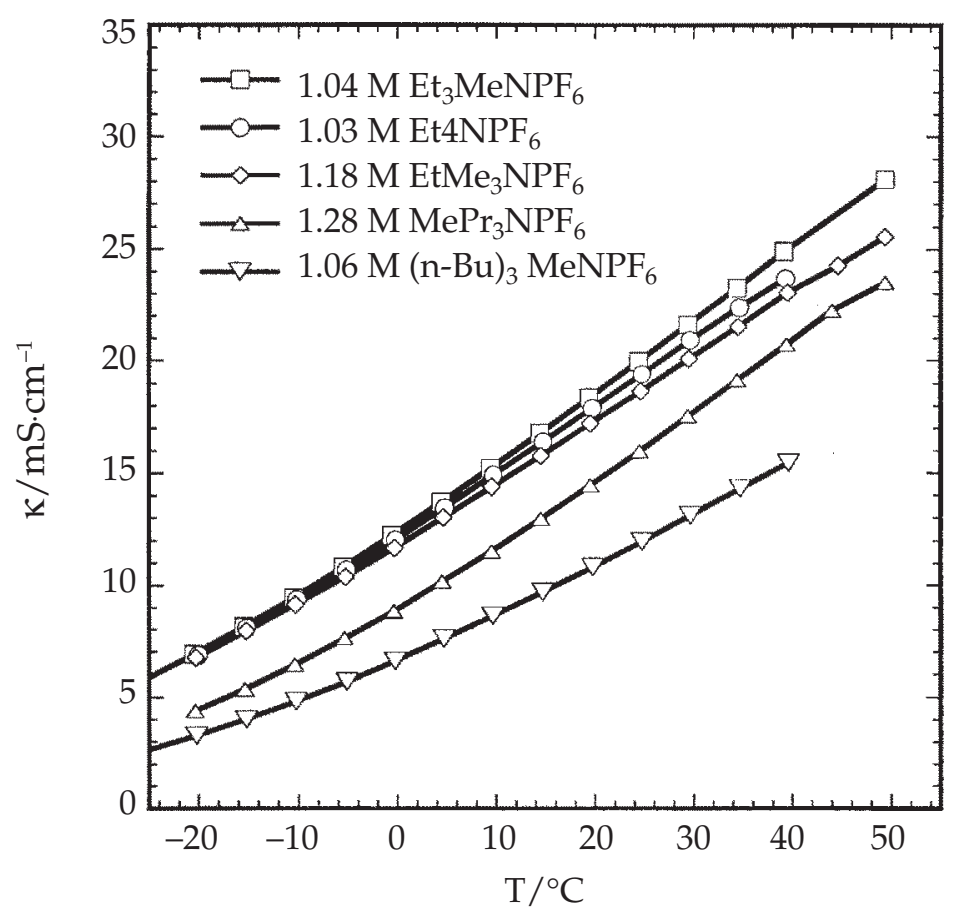

Figure 4.6: Change of conductivity with the size of the cations in tetraalkylammonium hexafluorophosphates for EC-DMC (50:50 by wt.) electrolytes containing such salts. 
Limiting molar conductivities of the two salts in EC-DMC solvent at different temperatures are plotted in figure 4.7. These conductivities have been obtained by extrapolating to infinite dilution the molar conductivities of the two electrolytes measured with the two dilute electrolytes. In the temperature range measured, the values of $\mathrm{Et}_{3} \mathrm{MeNPF}_{6}$ salt are slightly larger than those of $\mathrm{Et}_{4} \mathrm{NPF}_{6}$ salt, and both show almost linear temperature dependence. Figure 4.7 shows the limiting molar conductivities of these two electolytes (28) and those of $\mathrm{LiPF}_{6}$ solu- $^{-}$ tions of the same solvent. Compared to the latter, the densities of the two ammonium salt electrolytes are significantly smaller and very close to each other.

\subsection{Electrochemical Stability}

\section{Electrochemical Stability versus Glassy Carbon}

The limiting reduction potential $E_{r e d}$ and the oxidation potential $E_{o x}$ of each electrolyte were measured in a three-electrode cell using a linear sweep voltammetry technique. A glassy carbon rod and a platinum sheet were used as the working and the counter electrodes, respectively. A piece of lithium metal was used as a reference electrode.

Results of the electrochemical stability measurements with linear sweep voltammetry with glassy carbon working electrodes are shown in figure 4.8 for the two electrolytes in the same EC-DMC solvent but with $1 \mathrm{M}$ salts of $\mathrm{Et}_{4} \mathrm{NPF}_{6}$ and $\mathrm{Et}_{3} \mathrm{MeNPF}_{6}$, respectively. It can be seen that both salts have stability windows more than $6.5 \mathrm{~V}$ wide. Close inspection of the results shows that the two salts have almost identical reductive stabilities in EC-DMC solvent on glassy carbon. The stability window of $1 \mathrm{M} \mathrm{Et}_{4} \mathrm{NPF}_{6}$ in $\mathrm{AN}$ is also included for comparison. The oxidative stability of this electrolyte is more than $1 \mathrm{~V}$ lower than that of the electrolyte containing EC-DMC solvent.

As shown in figure 4.9, the limiting reduction potentials of various quaternary ammonium salts containing either symmetric or asymmetric cations such as $\mathrm{Et}_{4} \mathrm{~N}^{+}, \mathrm{Me}_{3} \mathrm{EtN}^{+}$,

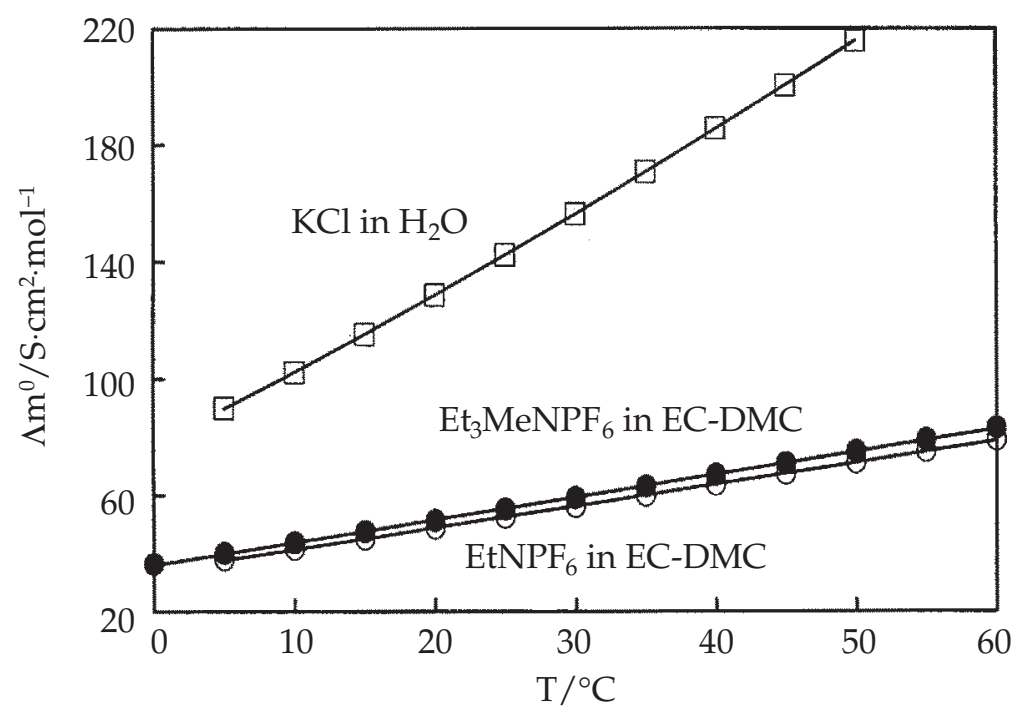

Figure 4.7: Limiting molar conductivities of two electrolytes, $\mathrm{Et}_{3} \mathrm{MeNPF}_{6}$ and $\mathrm{Et}_{4} \mathrm{NPF}_{6}$, respectively, in EC-DMC (50:50) at different temperatures. Those of $\mathrm{KCl}$ in water are plotted for reference and comparison. 


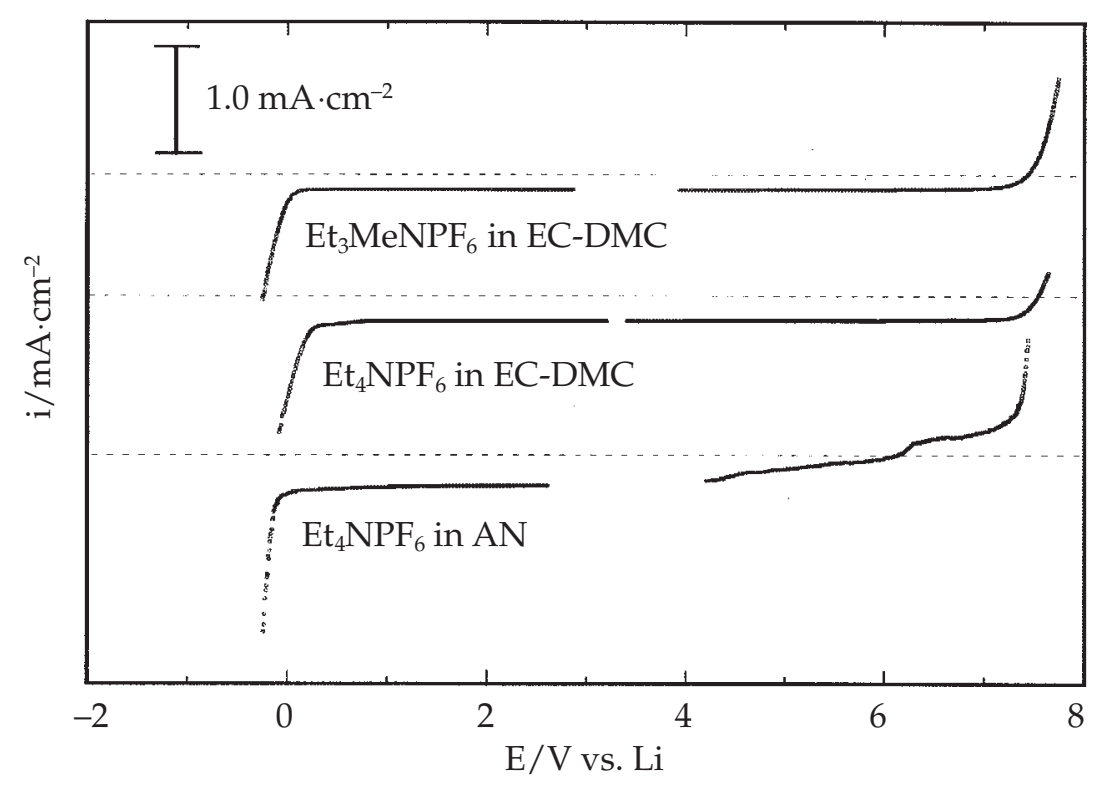

Figure 4.8: Linear sweep voltammograms for electrolyte solutions of $\mathrm{Et}_{4} \mathrm{NPF}_{6}$ and $\mathrm{Et}_{3} \mathrm{MeNPF}_{6}$ in EC-DMC (50:50) on glassy carbon. That for $\mathrm{Et}_{4} \mathrm{NPF}_{6}$ in $\mathrm{AN}$ is plotted for comparison.

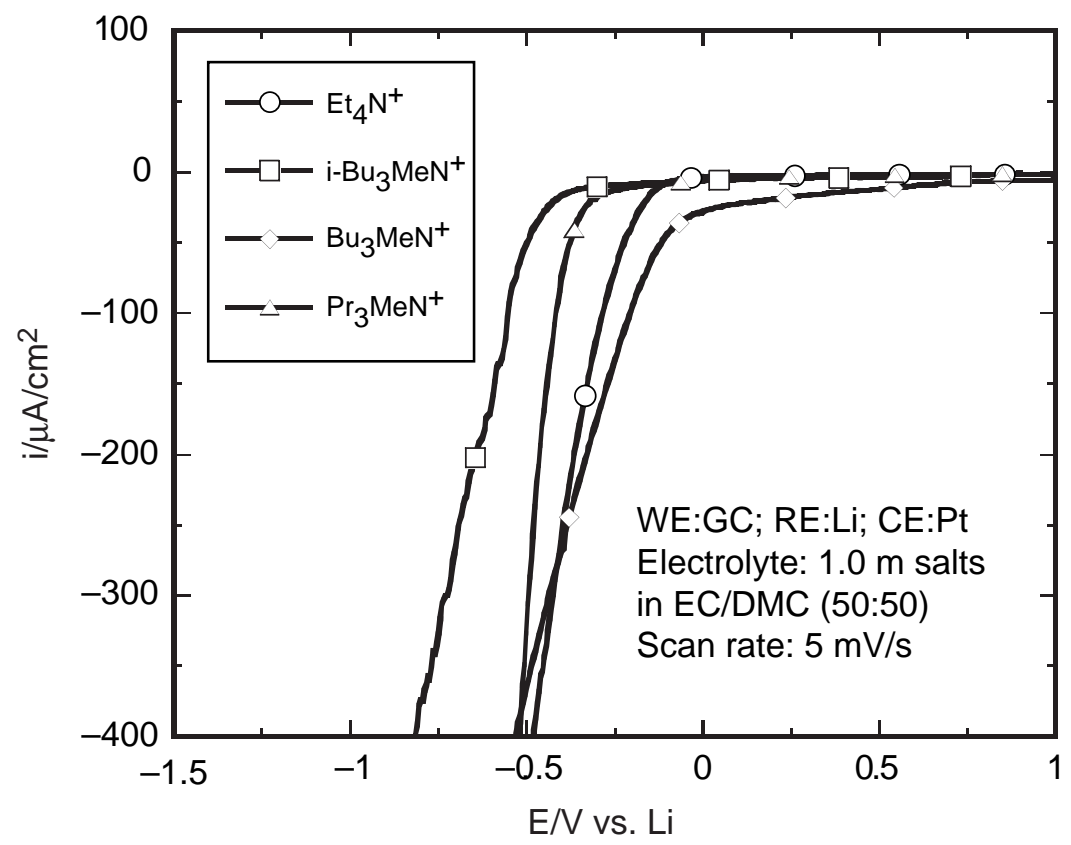

Figure 4.9: Comparison of cathodic stability of various onium cations synthesized.

$\mathrm{Et}_{3} \mathrm{MeN}^{+}, \mathrm{Pr}_{3} \mathrm{MeN}^{+}, \mathrm{Bu}_{3} \mathrm{MeN}^{+}$in $\mathrm{EC}-\mathrm{DMC}$ with $\mathrm{PF}_{6}{ }^{-}$anion exhibited similar values at about $-0.5 \mathrm{~V}$ versus $\mathrm{Li}^{+} / \mathrm{Li}$ (the voltage value at which the current reaches $500 \mu \mathrm{A} / \mathrm{cm}^{2}$ ) at a scan rate of $5 \mathrm{mV} / \mathrm{s}$ (27). These results indicate that the solvent also plays a role in the reductive stability of the electrolyte. When the asymmetric quaternary ammonium cation contains a more spatially hindered group such as $\mathrm{i}-\mathrm{Bu}_{3} \mathrm{MeN}^{+}$, the limiting reduction potentials were further extended from -0.5 to $-1.0 \mathrm{~V}$ versus $\mathrm{Li}^{+} / \mathrm{Li}$ as shown in figure 4.10 (27). 


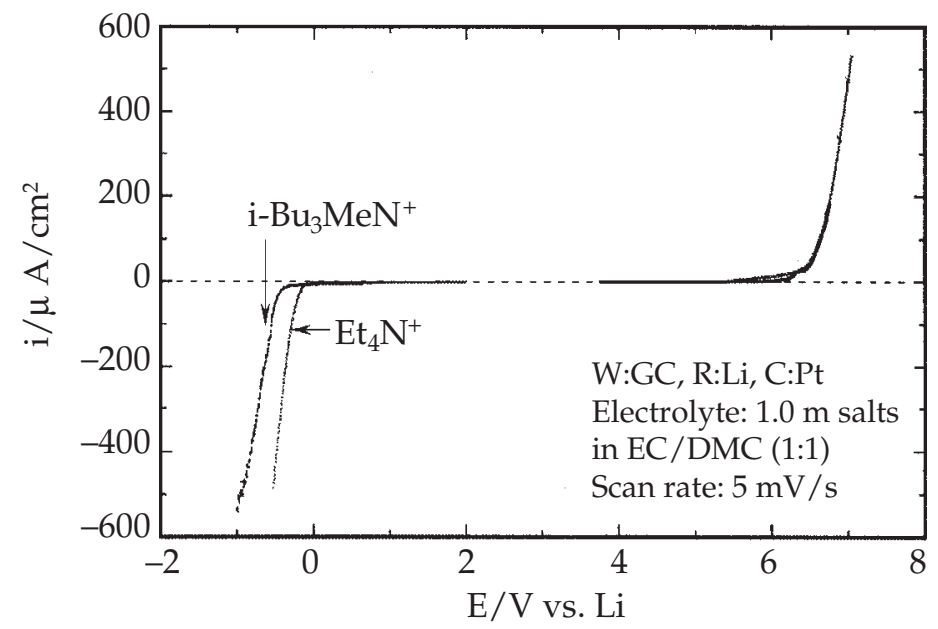

Figure 4.10: The total electrochemical stability window of a conventional ammonium salt and a new ammonium salt with steric hindrance.

The $E_{o x}$ values of the electrolytes containing quaternary ammonium salts were independent of the cations. We found, however, that they are dictated by the stability of anions or solvents. As shown in figure 4.11, the $E_{o x}$ of $\mathrm{PF}_{6}^{-}$anion is about $6.5 \mathrm{~V}$ versus $\mathrm{Li}^{+} / \mathrm{Li}$, which is about $1 \mathrm{~V}$ higher than that of trifluoromethylsulfonate $\left(\mathrm{CF}_{3} \mathrm{SO}_{3}{ }^{-} \mathrm{Tf}^{-}\right)$anion and bis(trifluoromethylsulfonyl)imide $\left(\left(\mathrm{CF}_{3} \mathrm{SO}_{2}\right)_{2} \mathrm{~N}^{-}\right.$, Im $)$anion.

\section{Electrochemical Stability versus Porous Activated Carbon Electrodes}

The electrochemical stability window of an electrolyte is usually determined by the limiting reduction and oxidation potentials of the electrolyte against a glassy carbon working electrode using a linear sweep voltammetry technique. The stability window values obtained by this method cannot be used to determine the safe operating voltage of a capacitor. Part of the reason for this is that the surface area of the glassy carbon is too low to produce a level of current that is high enough to tell that the instability has already occurred before the catastrophic decomposition. Furthermore, the surface properties of each activated carbon are different from that of a glassy carbon.

Using a porous electrode made of an activated carbon instead of a glassy carbon electrode presents a practical problem $(27,30)$. Instead of zero background current, we have observed a large and symmetric current (i.e., $Q_{A}=Q_{C}=Q_{N F}$, where $Q_{N F}$ is charge due to the reversible capacitive current or a non-Faradaic current) when the voltage scan is within the stability limits (see fig. 4.12). When the voltage scan went beyond the stability limits, the charge measured would include not only $Q_{N F}$ but also $Q_{F}$, which is the charge due to the irreversible electrolyte decomposition or a Faradaic current. Furthermore, we observed that the current measured did not increase but decreased as a result of the instability. This is because the Faradaic reaction between the electrolyte and the electrode reduced the available surface area of the activated carbon electrode before the catastrophic reactions occurred. Therefore, a new method to quantify the stability limits is needed. Instead of scanning the potential all the way to the limiting 


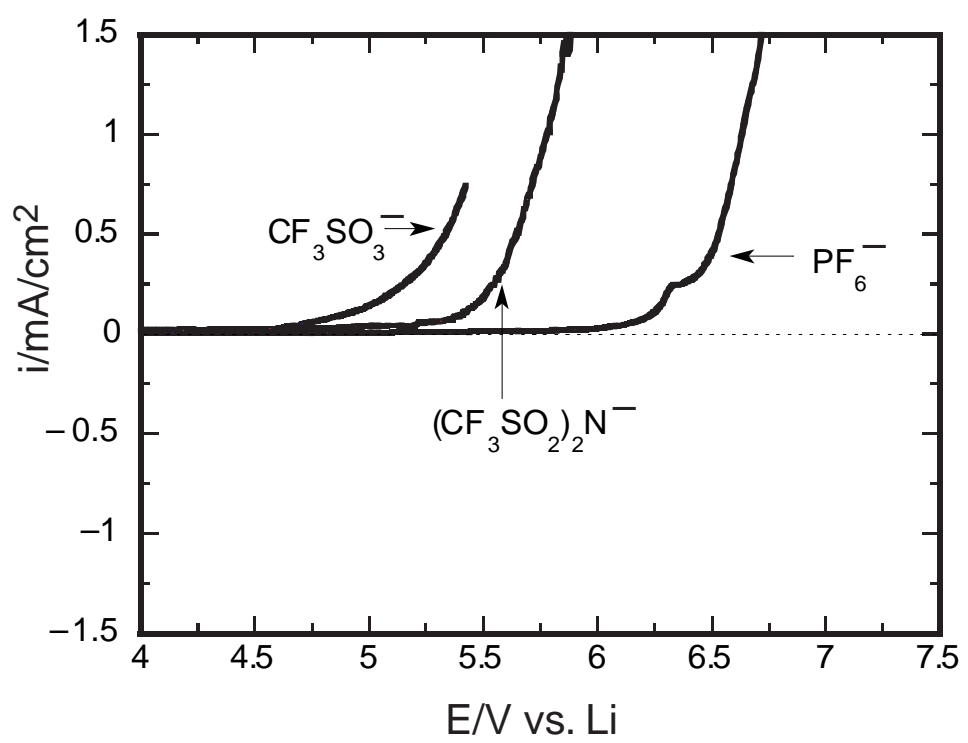

Figure 4.11: Comparison of anodic stability of various anions.

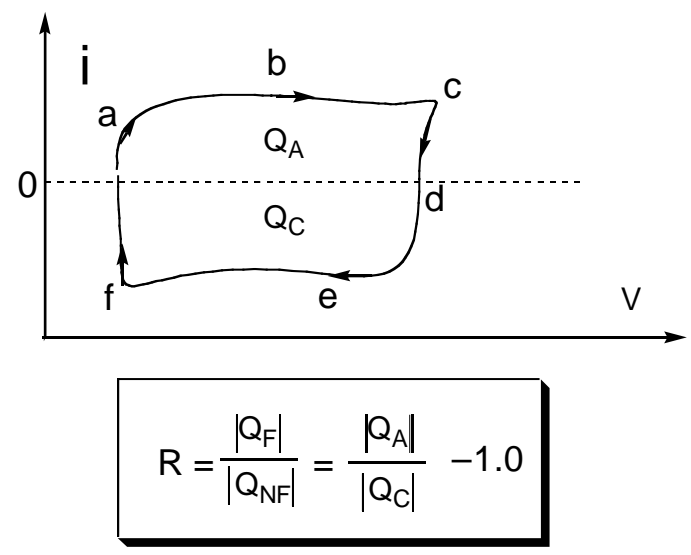

Figure 4.12: The CV curve of an electrolyte against a porous activated carbon electrode. Instead of a zero background current, a large background current was observed. Within the stability window, there is only non-Faradaic charge $Q_{N F}$, (or capacitive charging current) but no Faradaic charge $Q_{F}$. The $Q_{F}$-to- $Q_{N F}$ ratio, $R$, should be zero when the voltages are within the stability window.

potentials, we successively scanned the potential from a small value toward the limiting potentials. At each voltage scan, we use the ratio $\boldsymbol{R}$, which is defined as

$$
\boldsymbol{R}=\frac{\left|Q_{F}\right|}{\left|Q_{N F}\right|}=\frac{\left|Q_{A}\right|}{\left|Q_{C}\right|}-1.0,
$$

to judge whether the voltage is still within the stability limits. An $R$ thus defined will give the ideal value 0 as long as the Faradaic irreversible process is negligible, and will be greater than 0 in both the anodic or cathodic territories once the decomposition of the electrolyte starts occurring to a discernible extent. If a series of scans is done with successively increasing (or 
decreasing) voltage limits, then $\boldsymbol{R}$ of each scan is plotted versus the potential limit of that scan. This plot should accurately reflect the onset potential of any Faradaic process indicated by the deviation of $R$ from the ideal value 0 , as schematically depicted in figure 4.13.

Figure 4.14 shows the result of actually applying the procedure depicted by figure 4.13 to an electrolytic solution of 1.0 $\mathrm{M} \mathrm{Et}_{4} \mathrm{NPF}_{6}$ in 50:50 EC-DMC. By choosing an arbitrary reversibility limit of $\boldsymbol{R}=0.1$ (i.e., the decomposition of electrolyte accounts for $\sim 10 \%$ of the total charge infused into the capacitor), the electrochemical stability window of this electrolyte, which is now well defined, would be $2.71 \mathrm{~V}$, with reduction and oxidation potentials at $1.81 \mathrm{~V}$ and $4.52 \mathrm{~V}$ versus the Li reference electrode, respectively. At potentials lower than $1.0 \mathrm{~V}$ and higher than $5.0 \mathrm{~V}$ versus $\mathrm{Li} / \mathrm{Li}^{+}$, the electrolyte undergoes substantial decomposition, giving the maximum stability window of $\sim 4.0 \mathrm{~V}$. This value corresponds well with the actual working voltage limit of nonaqueous supercapacitors.

Several other nonaqueous electrolyte systems were evaluated by this new method using an asymmetrical tetraalkylammonium salt $\left(\mathrm{Et}_{3} \mathrm{MeN}^{+} \mathrm{PF}_{6}{ }^{-}\right)$as electrolyte solute, and the results are summarized in figure 4.15. With some slight variations, their stability windows all lay in the range of $\sim 1.5 \mathrm{~V}$ to $\sim 4.5 \mathrm{~V}$ versus $\mathrm{Li}$, with the exception of the ethylmethyl sulfone-containing electrolyte. This electrolyte is especially resistant to reduction and thus yields a stability window as wide as $3.64 \mathrm{~V}$. All these stability windows are obviously narrower than measured on nonporous electrodes and would more accurately reflect the real stability window in actual capacitor devices. Of special interest is the difference in the stability window of $\mathrm{Et}_{3} \mathrm{MeN}^{+} \mathrm{PF}_{6}{ }^{-}$ and $\mathrm{Et}_{4} \mathrm{~N}^{+} \mathrm{PF}_{6}{ }^{-}$in the same solvent 50:50 EC-DMC (compare fig. 4.14 and 4.15). The symmetrical salt cation $\left(\mathrm{Et}_{4} \mathrm{~N}^{+}\right)$shows a little more cathodic stability than its asymmetrical counterpart $\left(\mathrm{Et}_{3} \mathrm{MeN}^{+}\right)$, while this difference is hardly detectable on the glassy carbon working electrode. We attribute this different ability to resist cation reduction to the shielding effect of the central cation by its alkyl substituents, which will be discussed in more detail in our future publication (27).

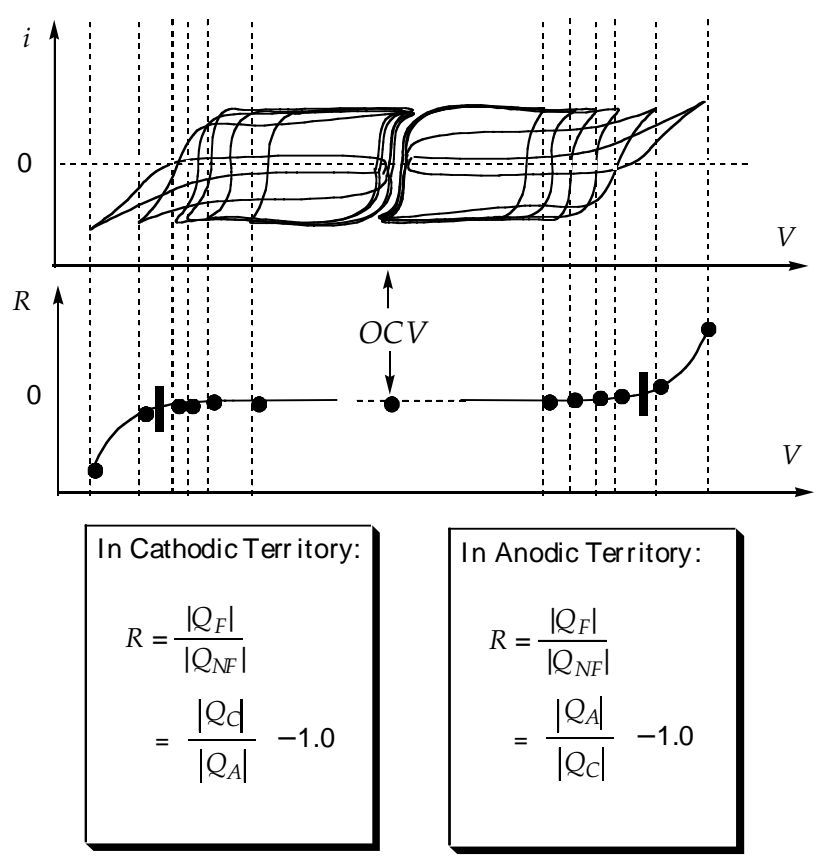

Figure 4.13: New method for the quantification of electrolyte stability range on activated carbon. 


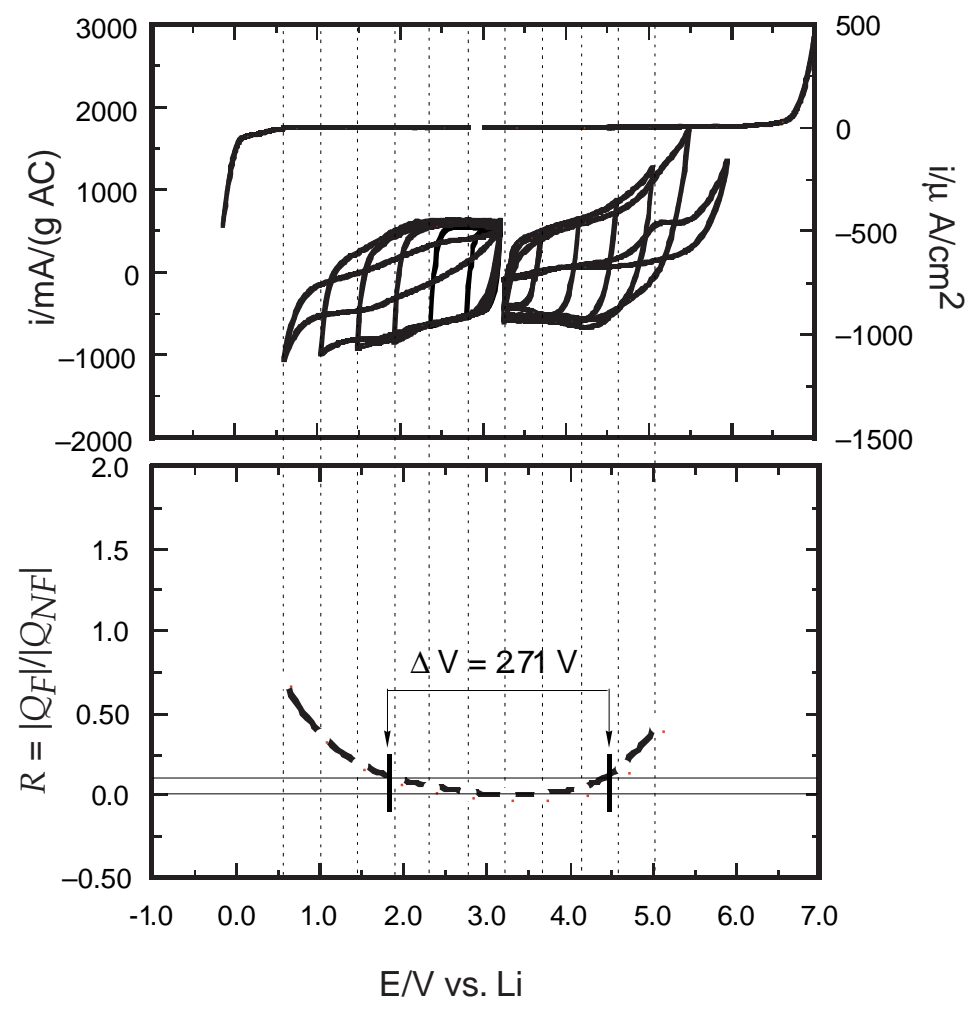

Figure 4.14: The electrochemical stability range of electrolyte $1.0 \mathrm{M} \mathrm{Et}_{4} \mathrm{NPF}_{6}$ in EC-DMC (50:50) according to the new quantification.

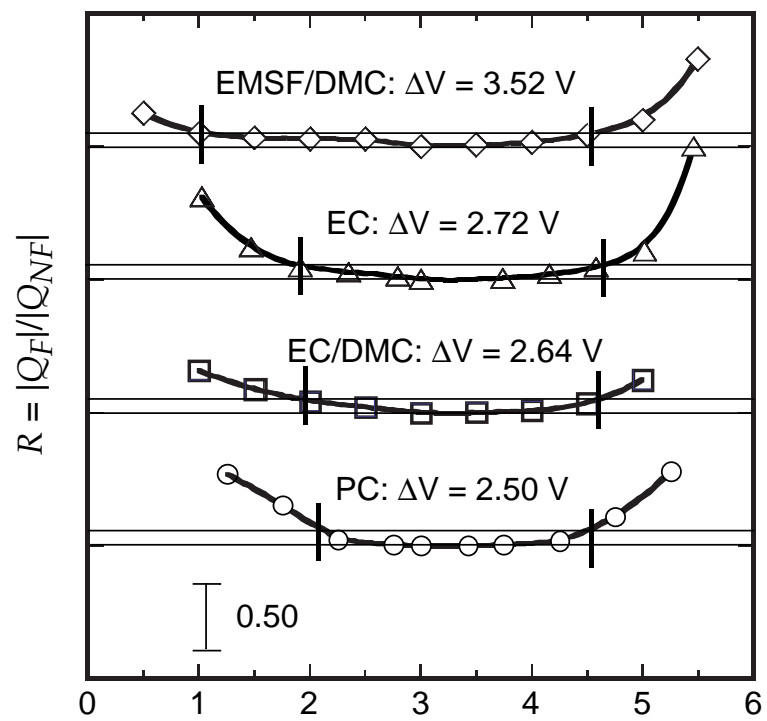

EN vs. Li

Figure 4.15: The electrochemical stability window of several electrolytes containing 1.0 $\mathrm{MEt}_{3} \mathrm{MeNPF}_{6}$ in solvent systems such as PC, EC-DMC, EC, and EMSF-DMC determined by the new quantification method. 


\subsection{Capacitance}

Capacitance values of carbon materials in electrolytes are insensitive to the dielectric constant of the solvent used. We found that the capacitance values of capacitors made with activated carbon electrodes in $0.65 \mathrm{M} \mathrm{Et}_{4} \mathrm{NBF}_{4}$ in $\mathrm{PC}, \mathrm{AN}$, and $\mathrm{MF} / \mathrm{AN}$ were $6.94,6.91$, and 6.72 F, respectively. The dielectric constants of PC, AN, and MF/AN are 64.4, 36.0, and 22.5, respectively. This result is consistent with the recent studies reported by McEwen et al. (29). They found that the specific capacitance values of carbon in $2 \mathrm{M}$ ethylmethyl imidazolium hexafluorophosphate $\left(\mathrm{EMIPF}_{6}\right)$ in EC, PC, DMC, EMC, EC-DMC $(1: 1 \mathrm{v} / \mathrm{v})$, and PC-EMC $(1: 1 \mathrm{v} / \mathrm{v})$ are $123,127,126,123,129$, and $129 \mathrm{~F} / \mathrm{g}$, respectively. As we note in table 3.1, the dielectric constants of EC and PC are 95 and 65, respectively, while that of DMC and EMC are 3.12 and 2.9 , respectively.

However, the capacitance measured was sensitive to the molecular size of the salt used. For example, capacitance values of 0.666 and $0.799 \mathrm{~F}$ were measured in electrolytes of $0.65 \mathrm{M}$ $\mathrm{Et}_{4} \mathrm{NBF}_{4} / \mathrm{PC}$ and $0.65 \mathrm{M} \mathrm{Et}_{4} \mathrm{NSCN} / \mathrm{PC}$, respectively. The larger capacitance value measured with the $\mathrm{SCN}^{-}$anion is attributed to its smaller ion size.

The double-layer capacitance that we have measured was about 130 to $150 \mathrm{~F} / \mathrm{g}$ for an Osaku Gas M30 activated carbon in quaternary ammonium salts containing cation with different structures (or alkyl groups) in EC-DMC. We have not observed significant capacitance value changes as a result of changes in cation size of the asymmetric quaternary ammonium cation in the salt. Since the capacitance measured is a reflection of the effect of both cation and anion, the impact from the cation alone may not be sufficient to show the difference. However, we should note a recent report by Morita et al. (9). Their model capacitors showed a value of $10 \mathrm{~F} / \mathrm{g}$ in $0.5 \mathrm{M} \mathrm{Bu}_{4} \mathrm{NBF}_{4}$ in EC- $\gamma \mathrm{BL}$, while a value of $16 \mathrm{~F} / \mathrm{g}$ was shown in $0.5 \mathrm{M} \mathrm{Et}_{4} \mathrm{NBF}_{4}$ in EC- $\gamma \mathrm{BL}$.

\subsection{A Comparison of ARL Electrolytes With the State-of-the-Art Electrolytes}

The electrolytes that we developed under this project that exhibited the best combination of salt concentration and electrochemical stability window are listed in table 4.3. The state-ofthe-art electrolytes are also listed for comparison. The energy density calculated with equation [2] reaches as high as $20 \mathrm{Wh} / \mathrm{kg}$ counting only the electrode material and the electrolyte, where the salt concentration is $1.5 \mathrm{M} / \mathrm{kg}$ and the operating voltage is $3.5 \mathrm{~V}$. We did not have sufficient time for further search of solvents for our new salts in this project. However, the identification of EMSF as a more stable solvent is an important discovery. This clearly suggests that more effort is needed in the area of solvents. A recent report by Hirahara et al. (31) confirms our belief that the electrode material is also critical in determining the operating voltage and the stability of the electrochemical capacitor at elevated temperatures.

\subsection{Cell Performance}

After vigorous drying, the electrodes and the separator were vacuum-soaked with an electrolyte containing $\mathrm{Et}_{3} \mathrm{MeNPF}_{6}$ in EC-DMC and were assembled as an experimental capacitor cell. Figure 4.16 shows the voltage profile for galvanostatic charging/discharging of such a capacitor that comprises the electrolytes that were developed in this project. The charge/ 
discharge were carried at different operating voltages, and eventually the voltage was deliberately brought over the decomposition potential of the electrolytes. While Panasonic's

GoldCap ${ }^{\circledR}$, capacitor burst the safety valve at $\sim 4.0 \mathrm{~V}$ charging, the electrolytes developed in this project operated well at $4.0 \mathrm{~V}$, and did not burst even at $5.0 \mathrm{~V}$ in a cell with the same safety valve.

We planned to test prototype capacitors of a size of 100 F/2.3 V from Maxwell Technologies with our electrolytes. Our specific interests are stability of the capacitor under voltage bias from 2.3 to $3.0 \mathrm{~V}$ at elevated temperatures of about 40 to $60^{\circ} \mathrm{C}$ and the performance of the capacitors at low temperatures of about -10 to $-30^{\circ} \mathrm{C}$. However, the amount of purified electrolyte and the time to complete the above tests were beyond the scope of the present project.

Table 4.3: A comparison of ARL electrolytes with the state-of-the-art electrolytes.

ARL electrolyte

\begin{tabular}{|c|c|c|c|c|c|c|c|}
\hline Salt & Solvent & $C(\mathrm{M} / \mathrm{kg})$ & $c_{p}(\mathrm{~F} / \mathrm{g})$ & $\sigma(\mathrm{mS} / \mathrm{cm})$ & $\Delta V(\mathrm{~V}): \mathrm{GC}$ & $\Delta V(\mathrm{~V}): \mathrm{AC}$ & $\varepsilon(\mathrm{Wh} / \mathrm{kg})$ \\
\hline$\overline{\mathrm{Et}}_{3} \mathrm{MeNPF}_{6}$ & EMSF-DMC & 1.5 & 120 & - & - & 3.50 & 20.33 \\
\hline $\mathrm{Pr}_{3} \mathrm{MeNPF}_{6}$ & EC-DMC & 1.28 & 120 & 14 & 6.78 & 3.04 & 15.55 \\
\hline $\mathrm{Et}_{3} \mathrm{MeNPF}_{6}$ & EC-DMC & 1.5 & 120 & 19 & 6.54 & 2.50 & 12.79 \\
\hline \multicolumn{8}{|c|}{ State-of-the-art electrolyte } \\
\hline $\mathrm{Et}_{4} \mathrm{NBF}_{4}$ & PC & $\begin{array}{l}0.72 \\
(0.75 \mathrm{M})\end{array}$ & 120 & 10 & $6.15^{a}$ & $2.9^{a}$ & 9.99 \\
\hline $\mathrm{Et}_{4} \mathrm{NBF}_{4}$ & AN & $\begin{array}{l}3.85 \\
(1.68 \mathrm{M})\end{array}$ & 120 & 57 & $3.5-4.0^{\mathrm{a}}$ & $2.0^{\mathrm{a}}$ & 12.60 \\
\hline $\mathrm{EMIPF}_{6}$ & PC & $\begin{array}{l}2.62 \\
(2 \mathrm{M})\end{array}$ & 120 & 16 & $4.5^{\mathrm{a}}$ & $2.0^{\mathrm{a}}$ & 11.30 \\
\hline
\end{tabular}

astimated value.

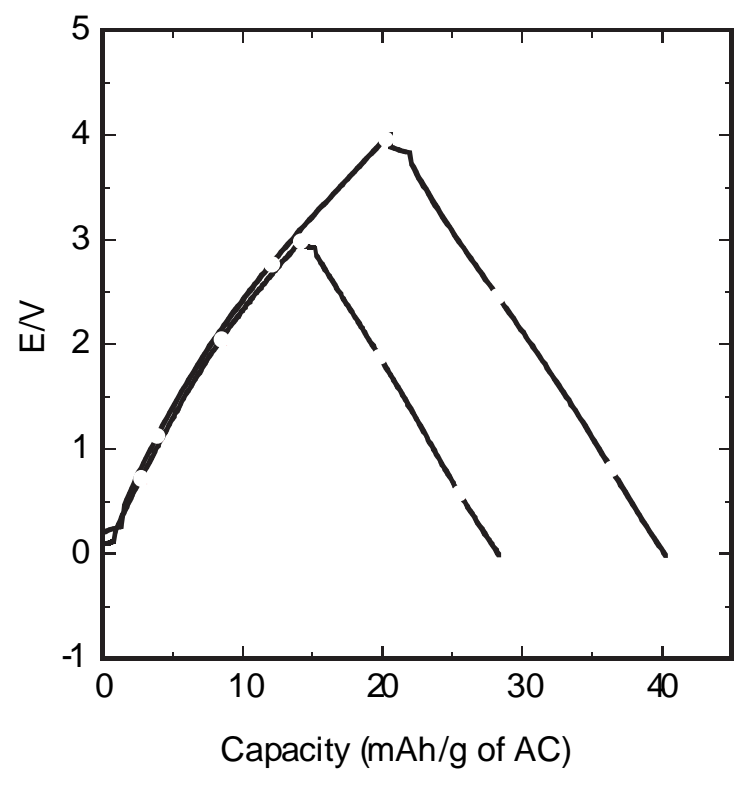

Figure 4.16: Charge/discharge voltage profile of a Panasonic GoldCap®, capacitor in original electrolyte (lower curve) and in $1.0 \mathrm{M} \mathrm{Et}_{3} \mathrm{MeNPF}_{6}$ in ECDMC (upper curve). 


\section{Conclusions and Future Perspective}

Nonaqueous electrolytes were formulated and evaluated for double-layer capacitors. For a commercially available salt, $\mathrm{Et}_{4} \mathrm{NBF}_{4}$, the more promising solvents were a blend of ethylene carbonate (high dielectric constant) and a second low-viscosity liquid. Several formulations were prepared with a conductivity over $15 \mathrm{mS} / \mathrm{cm}$, a salt concentration over $1 \mathrm{M}$ (1.4 to $1.6 \mathrm{M})$, and an electrochemical stability window of over $6.5 \mathrm{~V}$ against a glassy carbon electrode.

With the change in cation from symmetric ones to asymmetric ones in quaternary ammonium salts, we have shown that a significant change in solubility occurs in EC-DMC that ranges from 1.4 M to 2.2 M. A conductivity peak of the electrolyte is shifted to a higher salt concentration for the asymmetric cation. A conductivity value as high as $22 \mathrm{mS} / \mathrm{cm}$ has been achieved. The ion size of the cation affects the solubility and the conductivity of the electrolytes containing these salts. Salts containing a spatially hindered cation, $\mathrm{i}-\mathrm{Bu}_{3} \mathrm{MeNPF}_{6}$, exhibited a limiting reduction potential $0.5 \mathrm{~V}$ larger than other asymmetric cations.

Since the electrochemical stability window values obtained for electrolytes normally use a glassy carbon electrode as a working electrode, the values obtained by such a method-for example, $6.5 \mathrm{~V}$-are often much larger than the real operating voltages-for example, 2.3 to 3.0 V. To obtain a realistic value of the stability window for a practical carbon material, the traditional method of using an arbitrary current value as a limit to determine the voltage limit does not work for the high surface area carbon materials. A new method that uses charge, or an integration of current, instead of using current directly to detect the instability limit gave us values that more realistically reflect the true stability window. Using the new method and a new salt, we learned that the stability window of the electrolyte varies with solvent too. Our study was not exhaustive; however, our discovery that the sulfone-based solvent achieved a stability window as high as $3.5 \mathrm{~V}$ is important.

The high salt concentration together with the large operating voltage window lead to high energy density and high power density capacitors. Demonstration of the new electrolytes in practical capacitors is certainly needed. Looking forward, more effort in the study of a solvent for low-temperature performance is needed. For high-temperature stability and high-voltage operations, studies of both solvent and carbon electrode materials are needed. For the next phase, the participation of a capacitor manufacturer for carbon electrode fabrication and capacitor assembly and a chemical company for electrolyte preparation and purification will speed up the development of high-energy and high-power electrochemical capacitors. 


\section{References}

1. T. R. Jow, "High Energy Density Capacitors Based on Electrostatic Energy," Proceedings of the 2nd International Seminar on Double Layer Capacitors and Similar Energy Storage Devices, Deerfield Beach, FL (December 7-9, 1992).

2. T. R. Jow and J. P. Zheng, "Electrochemical Capacitors Based on Amorphous Ruthenium Oxide," Proceeding of the $4^{\text {th }}$ International Seminar on Double Layer Capacitors and Similar Energy Storage Devices, Deerfield Beach, FL (December 12-14, 1994).

3. J. P. Zheng and T. R. Jow, "A New Charge Storage Mechanism for Electrochemical Capacitors," J. Electrochem. Soc., 142 (1), L6 (1995).

4. J. P. Zheng and T. R. Jow, "High Energy and High Power Density Electrochemical Capacitors," J. Power Sources, 62/2, 155 (1996).

5. T. R. Jow and J. P. Zheng, "Electrochemical Capacitors Using Hydrous Ruthenium Oxide and Hydrogen Inserted Ruthenium Oxide," J. Electrochem. Soc., 145 (1), 49 (1998).

6. A. Yoshida and K. Imoto, Electric Double Layer Capacitor and Method for Producing the Same, U.S. patent No. 5,150,283, issued to Matsushita Electric Industrial Co., Japan (September 22, 1992).

7. J. P. Zheng, J. Huang, and T. R. Jow, "The Limitations of Energy Density for Electrochemical Capacitors," J. Electrochem. Soc., 144(6), 2026 (1997).

8. J. P. Zheng and T. R. Jow, "The Effect of Salt Concentration in Electrolytes on the Maximum Energy Storage for Double Layer Capacitors," J. Electrochem. Soc., 144(7), 2417 (1997).

9. M. Morita, M Goto, and Y. Matsuda, "Ethylene Carbonate-Based Organic Electrolytes for Electric Double Layer Capacitors," J. Appl. Electrochemistry, 22, 901 (1992).

10. C. J. Farahmandi and J. M. Dispennette, High Performance Double Layer Capacitors Including Aluminum Carbon Composite Electrodes, U.S. patent No. 5,621,607, issued to Maxwell Laboratories, Inc., USA (April 15, 1997).

11. M. Ue, M. Takeda, M. Takehara, and S. Mori, "Properties of New Quaternary Ammonium Salts for Electrochemical Capacitors," Electrochemical Capacitor II, PV96-25, The Electrochemical Society Proceedings Series, Pennington, NJ (1997).

12. M. Ue, M. Takeda, M. Takehara, and S. Mori, "Electrochemical Properties of Quaternary Ammonium Salts for Electrochemical Capacitors," J. Electrochem. Soc., 144, 2684 (1997).

13. M. Ue, K. Ida, and S. Mori, "Electrochemical Properties of Organic Liquid Electrolytes Based on Quaternary Onium Salts for Electrical Double Layer Capacitors," J. Electrochem. Soc., 141, 2989 (1994).

14. A. B. McEwen, H. L. Ngo, J. L. Goldman, T. Blakley, and W. F. Averill, "Nonaqueous Electrolytes and Novel Packaging Concepts for Electrochemical Capacitors," The $7^{\text {th }}$ International Seminar on Double Layer Capacitors and Similar Energy Storage Devices, Deerfield Beach, FL (December 8-10, 1997). 
15. A. B. McEwen, S. F. McDevitt, and V. R. Koch, J. Electrochem. Soc., 144, L84 (1997).

16. A. B. McEwen, R. Chadha, T. Blakley, and V. R. Koch, Electrochemical Capacitor II, PV96-25, The Electrochemical Society Proceedings Series, Pennington, NJ (1997), p 313.

17. J. Fuller, R. T. Carlin, and R. A. Osteryong, "The Room Temperature Ionic Liquid 1-Ethyl-3Methylimindazolium Teterafluoroborate: Electrochemical Couples and Physical Properties," J. Electrochem. Soc., 144, 3881 (1997).

18. V. R. Koch, L. A. Dominey, C. Nanjundiah, and M. J. Ondrechen, J. Electrochem. Soc., 143, 788 (1996).

19. J. March, Advanced Organic Chemistry, $3^{\text {rd }}$ ed., John Wiley \& Sons, New York (1985).

20. H. House, Modern Synthetic Chemistry, $2^{\text {nd }}$ ed., W. A. Benjamin, Menlo Park, CA (1992).

21. Houben-Weyl, Methoden der organischen Chemie, Bd. IX, Thieme Verlag, Stuttgart (1995).

22. A. Hiers, Organic Synthesis, John Wiley \& Sons, New York (1932).

23. S. Mori, K. Ida, M. Ue, Process for Producing Quaternary Salts, U.S. patent No. 4,892,944 (1990).

24. D. Linden, Handbook of Batteries, $2^{\text {nd }}$ ed., McGraw-Hill, New York (1994).

25. S. P. Ding, K. Xu, and T. R. Jow, "Comparison of Properties of a Symmetric and Asymmetric Tetraalkylammonium Salt and Their Nonaqueous Electrolytes," Proceedings of the Symposium on Batteries for the $21^{\text {st }}$ Century, the $194^{\text {th }}$ Meeeting of The Electrochemical Society, Boston, MA (November 1-6, 1998).

26. C. Kittel, Introduction to Solid State Physics, $6^{\text {th }}$ ed., John Wiley \& Sons, Inc., New York (1986) p 67.

27. K. Xu, S. P. Ding, and T. R. Jow, "Quaternary Ammonium and Phosphonium Salts and Evaluation of Electrochemical Stability in Double Layer Capacitors" submitted to J. Electrochem. Soc.

28. S. P. Ding, K. Xu, and T. R. Jow, "Conductivity of Asymmetric Quaternary Ammonium Salts in Binary Carbonates," to be submitted to J. Electrochem. Soc.

29. A. B. McEwen, H. L. Ngo, J. L. Goldman, T. Blakley, and W. F. Averill, "Nonaqueous Electrolytes and Novel Packaging Concepts for Electrochemical Capacitors," Proceedings of the $7^{\text {th }}$ International Seminar on Double Layer Capacitors and Similar Energy Storage Devices, Deerfield Beach, FL (December 8-10, 1997).

30. K. Xu, S. P. Ding, and T. R. Jow, “Toward Reliable Values of Electrochemical Stability Limits for Electrolytes," submitted to J. Electrochem. Soc.

31. S. Hirahara, K. Okuyama, M. Suzuki, K. Matsuura, and Y. Takeda, "High Energy Density Double-Layer Capacitor by Li-Doping Techniques," Abstract No. 82, The $194^{\text {th }}$ Meeting of the Electrochemical Society, Boston, MA (November 1-6, 1998). 